\title{
QUEEN'S
UNIVERSITY
BELFAST
}

\section{A probabilistic fleet analysis for energy consumption, life cycle cost and greenhouse gas emissions modelling of bus technologies}

Harris, A., Soban, D., Smyth, B., \& Best, R. (2020). A probabilistic fleet analysis for energy consumption, life cycle cost and greenhouse gas emissions modelling of bus technologies. Applied Energy, 261, [114422]. https://doi.org/10.1016/j.apenergy.2019.114422

Published in:

Applied Energy

Document Version:

Peer reviewed version

Queen's University Belfast - Research Portal:

Link to publication record in Queen's University Belfast Research Portal

\section{Publisher rights}

Copyright 2020 Elsevier Ltd.

This manuscript is distributed under a Creative Commons Attribution-NonCommercial-NoDerivs License

(https://creativecommons.org/licenses/by-nc-nd/4.0/), which permits distribution and reproduction for non-commercial purposes, provided the author and source are cited.

\section{General rights}

Copyright for the publications made accessible via the Queen's University Belfast Research Portal is retained by the author(s) and / or other copyright owners and it is a condition of accessing these publications that users recognise and abide by the legal requirements associated with these rights.

Take down policy

The Research Portal is Queen's institutional repository that provides access to Queen's research output. Every effort has been made to ensure that content in the Research Portal does not infringe any person's rights, or applicable UK laws. If you discover content in the Research Portal that you believe breaches copyright or violates any law, please contact openaccess@qub.ac.uk. 


\title{
What can a Fleet Analysis Approach Add to the Life Cycle Modelling of Bus Technologies?
}

\author{
Andrew Harris ${ }^{1, *}$, Danielle Soban ${ }^{1}$, Beatrice M. Smyth ${ }^{1}$ and Robert Best ${ }^{2}$ \\ ${ }^{1}$ School of Mechanical and Aerospace Engineering, Queen's University Belfast, BT9 5AH, United Kingdom \\ ${ }^{2}$ Wrights Group Ltd, Ballymena, Co., Antrim, BT42 1PY, United Kingdom \\ *Correspondence: aharris07@qub.ac.uk
}

\begin{abstract}
Introducing alternative bus fleet technologies requires investigation into life cycle impacts, risks and benefits. Previous modelling approaches comparatively assess individual vehicle impacts, assuming alternative technologies can fulfil identical life cycle functions to a diesel baseline. This assumption neglects the influence that service frequency, capacity and range limitations have on daily operations and fleet and infrastructure sizing. The goal of this study was to develop a framework to investigate bus fleet operation in terms of the risk and uncertainty of an alternative drivetrain technology's ability to mitigate life cycle costs and greenhouse gas emissions. Probabilistic simulation enabled risk and uncertainty quantification of diesel, micro-hybrid, mildhybrid and battery-electric fleet scenarios for a UK case study. The fleet analysis approach revealed decreased potential to reduce life cycle costs and greenhouse gas emissions from battery-electric buses. Compared to a baseline single-deck diesel fleet at low risk levels, the micro-hybrid double-deck fleet delivers the largest life cycle cost savings (18.7\%). The largest life cycle greenhouse gas emissions savings come from the mild-hybrid lithium-titanate single-deck fleet $(20.8 \%)$. Double-deck micro and mild hybrid fleets are the most effective at saving both life cycle costs and greenhouse gas emissions. The modelling approach adds a novel probabilistic capability for making comparative fleet-wide assertions, supporting the decision-making process for implementing new fleet technologies.
\end{abstract}

Keywords: bus fleets; total cost of ownership; greenhouse gas emissions; life cycle modelling; life cycle assessment; risk and uncertainty.

$\begin{array}{llll}\text { Nomenclature and abbreviations } & & \\ \mathrm{BEB} & \text { battery electric bus } & \text { LFP } & \text { lithium iron phosphate } \\ \mathrm{CDF} & \text { cumulative distribution function } & \text { LTO } & \text { lithium titanate oxide } \\ \mathrm{Con} . & \text { conductive pantograph charging } & \mathrm{MGU} & \text { motor-generator unit } \\ \mathrm{CO}_{2} & \text { carbon dioxide } & \text { NMC } & \text { lithium nickel manganese cobalt oxide } \\ \mathrm{CO}_{2} \mathrm{e} & \text { carbon dioxide equivalent } & \text { O\&M } & \text { operation and maintenance } \\ \mathrm{DD} & \text { double-deck } & \text { Opp. } & \text { opportunity (charging) } \\ \text { EIO } & \text { economic input-output } & \text { SCC } & \text { social cost of carbon } \\ \text { ESS } & \text { energy storage system } & \text { SD } & \text { single-deck } \\ \text { GBP } & \text { British pound (£) } & \text { SOC } & \text { state-of-charge } \\ \text { GHG } & \text { greenhouse gas } & \text { TCO } & \text { total cost of ownership } \\ \text { GVW } & \text { gross vehicle weight } & \text { TfL } & \text { Transport for London } \\ \text { HEB } & \text { hybrid-electric bus } & \text { TIF } & \text { Technology Impact Forecasting } \\ \text { ICE } & \text { internal combustion engine } & \text { TTW } & \text { tank-to-wheel } \\ \text { Ind. } & \text { inductive charging } & \text { UC } & \text { ultracapacitor } \\ \text { LC-GHG life cycle greenhouse gas emissions } & \text { UK } & \text { United Kingdom } \\ \text { LCA } & \text { life cycle assessment } & \text { WTT } & \text { well-to-tank } \\ \text { LCC } & \text { life cycle costing } & \text { WTW } & \text { well-to-wheel }\end{array}$




\section{Background}

Unprecedented levels of anthropogenic greenhouse gas (GHG) emissions in the atmosphere are exacerbating the greenhouse effect, leading to global warming [1] and human health risks [2]. Energy supply and transport sectors are responsible for approximately $35 \%$ and $23 \%$ of global GHGs, respectively [3,4]. A modal shift from private to public transport [3] and adoption of alternative technologies are key solutions for mitigating climate impacts, and can also reduce urban congestion and improve air quality [5]. Buses remain the most widespread mode of public transport in the world [6]. Stricter environmental legislation [7,8] and volatile fuel costs [9] are moving bus fleet operators towards alternative drivetrains that reduce emissions and, potentially, operational costs, e.g. hybrid-electric buses (HEB) or battery electric buses (BEBs). However, when comparing new technologies, a common misleading assumption is that new bus fleets are a like-for-like replacement, regardless of their technological capabilities or route specific energy demands.

Charge scheduling [10], reduced passenger capacity and 'range anxiety' [10] are challenges for griddependent technologies. Extra BEBs may also be required to satisfy daily operation [11], leading to higher acquisition costs. Additional systems, e.g. refueling or charging infrastructure, battery replacements and depot upgrades, are not adequately accounted for in a vehicle-by-vehicle comparison. The potential life cycle benefits and risks associated with introducing new technologies into an established network therefore require detailed investigation [12]. Vehicles are often compared using life cycle modelling methods. Although life cycle analysis (LCA) and life cycle costing (LCC) address the potential environmental and economic impacts of a product's life cycle [13,14], these approaches do not predict absolute impacts [13], and thus fail to provide decision makers with a comprehensive view of the possible effects of decisions, i.e. deterministic assumptions [15]. Use of probabilistic and stochastic methods in life cycle frameworks can enhance the understanding of complex comparisons, uncertainty and variability between propulsion technologies [16].

The aim of this study is to develop a framework to investigate bus fleet operation in terms of the risk and uncertainty of an alternative drivetrain technology's ability to mitigate total cost of ownership (TCO) and life cycle greenhouse gas emissions (LC-GHG). In the context of this study, uncertainty is a state of limited knowledge, where possible states or outcomes can be quantified by assigning probabilities to these states or outcomes, and risk is therefore the quantified probability of an outcome occurring [17]. This study further aims to answer the research question, 'what can a fleet analysis approach add to the life cycle modelling of bus technologies?'. This paper contributes to the existing knowledge by developing a system-wide technology assessment framework that enables a novel probabilistic capability for making comparative fleet-wide assertions, challenging the status-quo of vehicle-by-vehicle comparisons and its implicit assumptions. Fleet operation in this paper is the provision of buses to transport passengers along a single daily bus route (for both peak and off-peak conditions) over a 12-year life cycle.

\subsection{Fleet Analysis Approaches in Bus Life Cycle Modelling}

For public transport planning, there are two basic requirements: the service must provide adequate transporting capacity for passenger volumes, and it must offer a certain minimum frequency of service [18]. There is a trade-off as operators can opt to increase the service frequency or the seating capacity of each vehicle [18]. Route scheduling therefore plays a critical role in determining the number of vehicles required, directly related to fixed and variable costs [19]. Previous research [20] showed how increasing passenger loading results in higher life cycle costs and GHG emissions for lower capacity vehicles when compared to a diesel equivalent due to additional vehicles required. Other work [21] highlighted the relationship between service frequency and capacity in fleets, finding lower off-peak operation demands to be practical for lower capacity, more efficient technologies, e.g. HEBs [21]. Likewise, Chan et al. [22] indicated that HEBs can reduce GHG emissions during peak operating times. These studies do not however consider the energy consumption variations resulting from uncertain vehicle design parameters, fluctuating passenger loads between peak and off-peak periods or assess BEBs.

Electricity-grid dependent technologies could affect the operational flexibility of bus services as existing schedules may need to be revised to suit charge scheduling [23]. Therefore, vehicle range capabilities will also determine fleet size. Lajunen [11] conducted a cost-benefit analysis of HEB and BEB fleets by simulating service frequency demands, operational range and recharging time for BEBs. For equivalent diesel fleet operation, one to two additional BEBs were necessary leading to higher TCO in all scenarios. Further studies expanded this analysis 
to assess life cycle costs and fuel cycle $\mathrm{CO}_{2}$ emissions of alternative fleet technologies [24] and to investigate BEB fleet life cycle costs for varying battery requirements, charging method (overnight, opportunity at bus stops and end-stations) and power [25]. End station charging of BEBs results in the lowest TCO of charging methods and may lead to lower TCO than diesel buses over the 12-year life. Fleet cost-effectiveness has been shown to vary with charging station placement and service frequency, but overall, larger fleets required at low service intervals increase TCO more aggressively than increasing battery capacity for additional range [26].

Other studies have sought to optimize mixed fleets on a whole transit network as opposed to a homogeneous fleet analysis [27-30], requiring the integration of complex models, but at the expense of increasing data requirements and calculation time not suitable for preliminary investigations. Given the uncertainty in a multidisciplinary exercise like life cycle modelling for immature technologies, it would be inappropriate to optimize to deterministic objectives [31]. To ensure an appropriate balance between model comprehensiveness and usefulness, any framework must enable system-wide decision-making with a minimum amount of initial inputs. Service frequency, vehicle capacity and range limitations must be accounted for when evaluating whole life impacts of alternative technologies. A gap has been identified: to develop a modelling capability that objectively assesses both life cycle costs and GHG emissions of alternative technologies under the fair functional unit of a fleet-lifetime. The capability will further evaluate if life cycle results deviate if it is assumed that a new technology could provide the same function as its diesel counterpart, a common implicit assumption in literature.

\subsection{Bus Life Cycle Modelling Approaches}

LCA tools have been used extensively to compare bus technologies, with two methods often utilised: process-based and economic input-output (EIO). Process-LCAs model the processes, material and energy inputs and environmental impacts from raw material acquisition to end-of-life. This exercise is difficult for vehicle LCAs and the system boundary is typically limited to a well-to-wheel (WTW) assessment [32], with studies often adapting established LCA tools, e.g. GREET [33] (used by [11,24,27,34-39]), AFLEET [40] (used by [27,34]), or GHGenius [41] (used by [22]). EIO-LCA is a 'top-down' approach which models the monetary transactions between economic sectors to quantify direct and indirect environmental impacts. The two methods can be combined into a third type, hybrid-LCA, leveraging the advantages of process-LCA for higher modelling fidelity in key life cycle phases (e.g. WTW and ESS replacements), but still covering an expansive system boundary [20,21,27,34,42-44]. Hybrid-LCAs are a complementary approach to LCC, with studies evaluating both economic and environmental impacts. For rapid preliminary assessments of a complex system such as bus fleets, a hybridLCA with LCC capabilities is appropriate.

Shifting focus from life cycle impacts at a vehicle level to the fleet level adds additional system complexity, leading to difficultly in capturing uncertainty of complex systems when constructing life cycle models [45]. Life cycle uncertainties, e.g. in operational factors that cause variation in energy consumption rate [46,47], have been previously assessed via Monte Carlo simulation techniques [48]. Ally and Pryor [49] quantified TCO uncertainty of alternative powertrains by assigning probability distributions to acquisition, fuel consumption, fuel price and maintenance costs. Göhlich et al. [50] developed a TCO model of urban electric bus systems and utilized a stochastic modelling approach to cope with forecasting uncertainties. No study, however, was identified that quantifies the risk and uncertainty associated with both economic and environmental impacts of alternative powertrain bus fleets in a comprehensive system boundary containing:

- GHG emissions ( $\mathrm{kgCO}_{2}$ ) : Bus manufacturing, WTW, maintenance, ESS replacements, charging infrastructure manufacturing, operation \& maintenance (O\&M).

- Costs (GBP converted to Euro): Vehicle capital, energy, maintenance, ESS replacements, infrastructure capital (including O\&M), driver labour and social cost of carbon (SCC).

\subsection{Technology Overview of Bus Powertrains Assessed}

This paper will focus on four main drivetrain technologies: conventional diesel, micro-hybrid, mild-hybrid and battery electric (Figure 1Error! Reference source not found.Error! Reference source not found.). These four architectures were selected due to the diverse modelling needs of individual subsystems that can be applied to other powertrain technologies in future framework iterations. 
(a) Conventional diesel bus

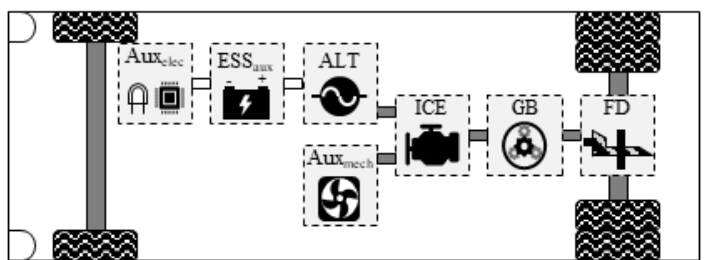

(c) Mild-hybrid diesel electric bus

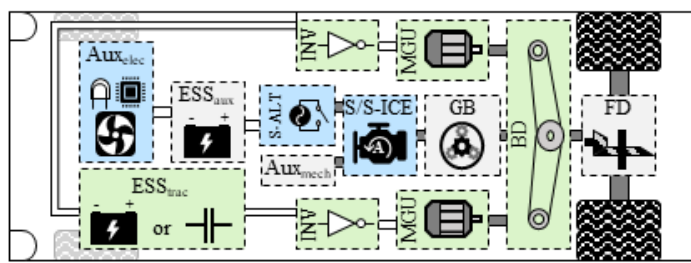

(b) Micro-hybrid diesel bus

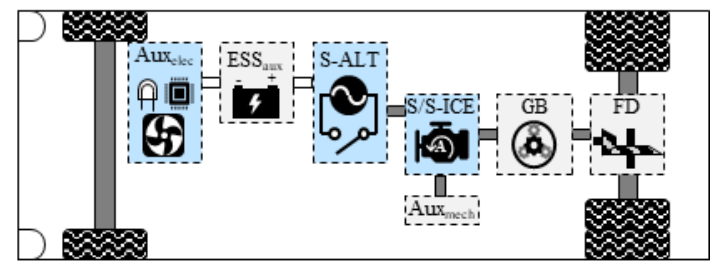

(d) Battery electric bus

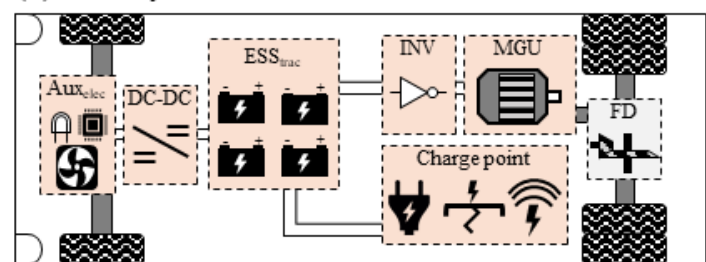

Key: $\mathrm{ICE}=$ internal combustion engine, $\mathrm{GB}=$ gearbox, $\mathrm{FD}=$ final drive, $\mathrm{ALT}=$ alternator, $\mathrm{ESS}=$ energy storage system, $\operatorname{Aux}_{\text {elec }}=$ auxiliary electrical devices, Aux mech $_{\text {m }}$ auxiliary mechanical devices, S/S-ICE = stop/start ICE, S-ALT = smart alternator, $\mathrm{INV}=$ inverters, $\mathrm{MGU}=$ motor-generator unit, $\mathrm{BD}=$ belt drive system, $\mathrm{DC}-\mathrm{DC}=$ direct current converter

Figure 1. Drivetrain architectures of (a) conventional diesel; (b) micro-hybrid; (c) mild-hybrid and; (d) battery electric bus configurations.

The conventional diesel ICE powertrain (Figure 1a) made up $96 \%$ of buses and commercial vehicles in Europe in 2016 [51]. Diesel is the conventional option for fleet operators due to high torque outputs at low speeds (suiting the stop-start nature of bus routes) and use of a widely available, energy dense fuel [52]. An attractive alternative to conventional diesel vehicles are 'micro-hybrids' that reduce fuel consumption and emissions via engine stop-start functionality, regenerative-braking and smarter electrified auxiliaries [53] (Figure 1b). They are not true hybrids as they do not provide tractive assistance, but are less expensive than more electrified drivetrains, can be retrofitted to existing diesel architectures [54], and allow manufacturers to meet legal and environmental requirements [55]. The micro-hybrids modelled in this study are Wrightbus micro-hybrid buses with a Euro VI stop-start engine, electrified air compressors, cooling fans and smart alternators [56].

As a 'stepping stone' towards full electrification, HEBs satisfy current transit service constraints [23] and offer a cost-effective means to meet the challenges of sustainable mobility with minimal disruption [57]. 'Mildhybrid' architectures (Figure 1c) offer cheaper acquisition costs than BEBs, with significant fuel and emissions reductions compared to diesel buses [58]. An ICE and motor-generator unit (MGU) simultaneously supply tractive power to assist with vehicle acceleration, but propulsion cannot be achieved via MGUs alone, powered by an ESS, i.e. battery or capacitor. The additional mass penalty incurred by the hybrid system is minimal and the low voltage ESS is relatively small compared to more sophisticated hybrid powertrains. Operators finding it financially difficult and impractical to deploy zero emission buses will view mild-hybrids as a cost effective, low emission option [59]. The mild-hybrids modelled are based on the Wrightbus 96-volt HEBs (a post-transmission parallel hybrid) building upon the micro-hybrid architectures with MGUs and an ESS [60].

BEBs are appealing to transit operators due to zero tailpipe emissions, increased system efficiency, enhanced performance on heavy duty 'stop-start' urban cycles, quiet operation and potential for lower maintenance costs [61] (Figure 1d). BEB uptake is inhibited by the initial capital cost, upwards of twice the investment of a Euro VI equivalent vehicle [11,23], and limited range. Increasing ESS capacity increases range, but could offset potential life cycle GHG savings due to the high environmental impact of battery manufacturing [62]. Battery energy densities are forecast to increase [63], meaning greater future range capabilities, but various charging strategies are being assessed in the short term. Opportunity charging, i.e. conductive or inductive [50], enables ESS downsizing, lowers vehicle capital and replacement costs and provides better service availability, but at a trade off with expensive high power infrastructure [43,64]. This paper explores the life cycle impacts of ESS chemistries and infrastructure configurations to enable further understanding of BEB technologies [30]. 


\section{Framework Development}

\subsection{Modelling Environment}

This study enhances previous framework developments by the authors which combined two methodologies: Technology Impact Forecasting (TIF) and life cycle modelling [43,44], by adapting an existing life cycle model to assess new drivetrains and scenarios [43]. Interconnected multidisciplinary sub-models simultaneously quantify fleet and vehicle results of the drivetrains for a given route (Figure 2Error! Reference source not found.). In a conscious decision to ensure an appropriate balance between model comprehensiveness and usefulness, the modelled case study is intended to showcase how the probabilistic framework enables preliminary decision making on a system-wide level. The following is an overview of the key model capabilities with the corresponding extensive algorithms are contained in the Supplementary Material (Section S1).

\subsubsection{Fleet Sizing Model}

The fleet sizing capability calculates the minimum fleet size required to fulfil frequency, capacity and range demands for two distinct operation periods: peak and off-peak service. The model is not intended to fully optimize the number of vehicles or supportive charging infrastructure, requiring data intensive and computationally expensive models $[10,24,65,66]$, but to simulate basic fleet operation with minimal inputs that can be obtained from existing departure schedules. Based on calculations by Lajunen [11] and Vepsäläinen et al. [26], the model assumes each fleet must complete a set number of peak and off-peak operational cycles (drive cycle time plus waiting time at end station), determined by the service frequency. A rotating dispatch schedule is assumed so equal peak and off-peak cycles are covered over the life cycle. Peak and off-peak capacity demands determine the average passenger loading per vehicle, an input into drive cycle energy demand models.

Range calculations focus primarily on BEBs, as it is assumed that all ICE technologies have sufficient diesel tank capacity to cover daily operation (limited to 18 hours per day to account for cleaning, inspection and refueling of the vehicle before the next day's service). The fleet model assumes that operators will prioritize bus availability for the start of the peak period and that there is no overlap or route-sharing with other fleets. The model evaluates the number of operational cycles that can be completed based on ESS capacity and available charging time and power at end stations. For depot-charged BEBs, the option of recharging smaller groups sequentially may become available depending on scheduling, meaning fewer chargers are needed. Additional opportunity chargers can feature to ensure equal recharging times for BEBs. If the number of vehicles and chargers satisfy peak operational demands, then they will satisfy off-peak demands.

\subsubsection{ESS Sizing Model for BEBs}

ESS sizing for BEBs is determined by an algorithm that calculates the ESS capacity needed to meet the energy demand over the peak drive cycle, as a function of ESS energy density, packing factor and the maximum passenger capacity without exceeding the gross vehicle weight (GVW) conditions. Energy recharged on-route informs downsizing capabilities for opportunity-recharged fleets. For both opportunity and depot charged fleets, ESS sizing further accounts for the allowable state-of-charge (SOC) operating window and the degradation over the ESS life. The sizing model is not used for mild-hybrids.

\subsubsection{Drive Cycle Energy Demand Models}

A quasistatic backward-facing drive cycle modelling approach is employed whereby the tractive power of the vehicle is calculated from a velocity trace and vehicle parameters. Backwards-facing simulations suit the intended rapid simplified investigations of vehicle energy consumption, but assume the vehicle and drivetrain

components achieve the desired velocity trace [67]. As the framework evaluates the impact of a new technology on a baseline system, vehicle masses are calculated via the addition or subtraction of key components to a conventional diesel vehicle [68]. Drive cycle energy demand models in this paper build upon previous diesel and BEB simulation models $[43,68]$ with micro and mild-hybrid functionalities added to the conventional diesel model. The conventional diesel architecture is theoretical and assumed to be as the micro-hybrid without any of the functionality. The micro and mild-hybrid control logic is simplified to suit the simulation times required for the overall life cycle model and does not represent the exact control logic on the vehicle. The control logic consists 
of a series of deterministic limits and constraints, which have been extracted from analysis of CAN data from onroad vehicle trials and dynamometer testing at Queen's University Belfast.

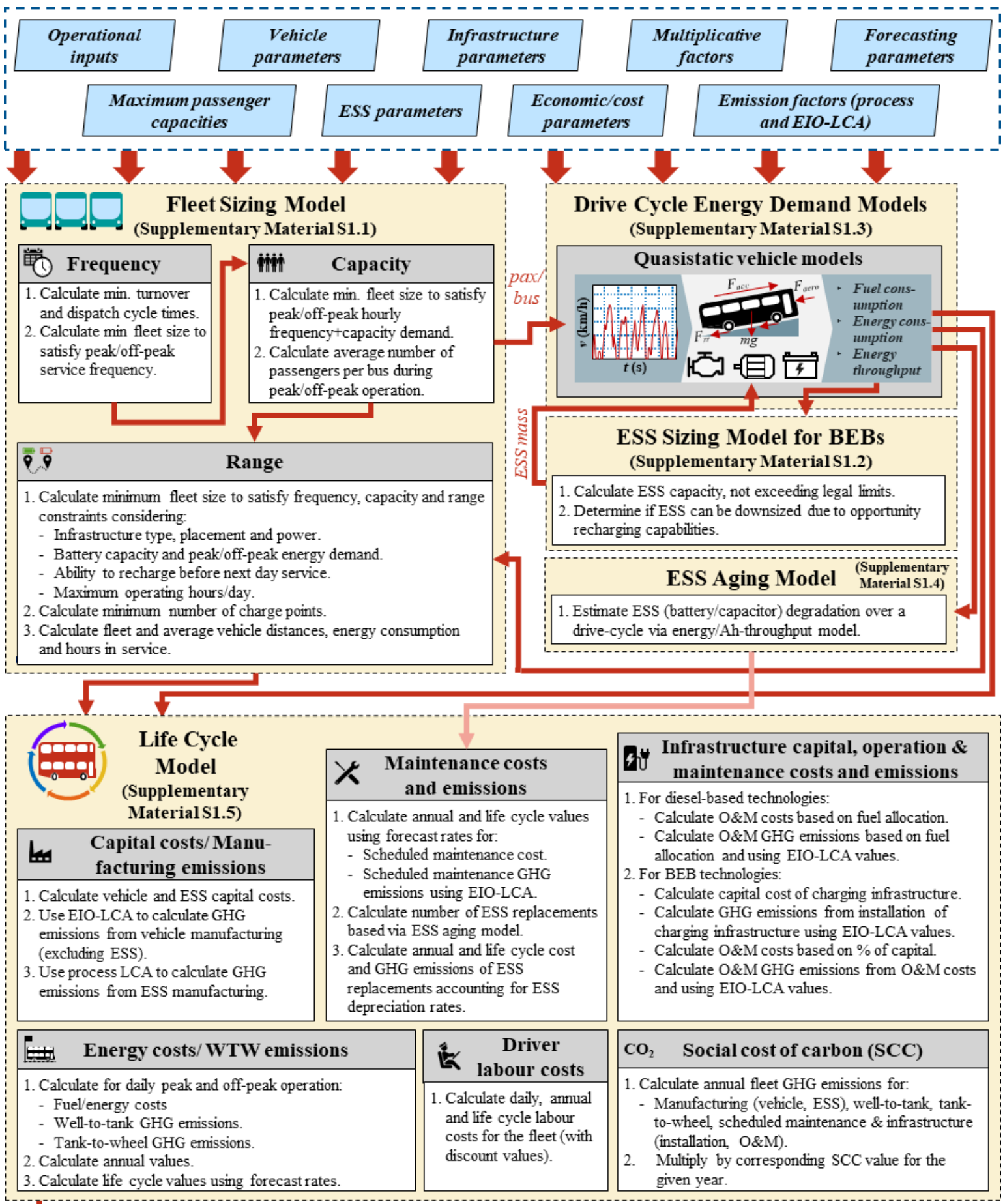

\begin{tabular}{|c|c|c|c|c|}
\hline$\Rightarrow+8$ & obabilistic & \multicolumn{3}{|c|}{ KEY OUTPUTS } \\
\hline & Imula & Life Cycle Costs & Life Cycle GHG emissions & Other Metrics \\
\hline \multicolumn{2}{|c|}{ Diagram Key } & - Maintenance (exc. ESS) & $\begin{array}{l}\text { - Well-to-tank } \\
\text { - Tank-to-wheel }\end{array}$ & $\begin{array}{l}\text { - Life cycle distance covered } \\
\text { - No. ESS replacements }\end{array}$ \\
\hline Input & Model & - Infrastructure (+O\&M) & - ESs replacements & No. on-route chargers \\
\hline Outnut & Model link & - Total Cost of Ownership (TCO) & emissions (LC-GHG) & \\
\hline
\end{tabular}

Figure 2. Overview of the life cycle modelling framework. 


\subsubsection{ESS Aging Model}

ESS replacements are calculated via an energy throughput model which assumes a finite amount of energy can be delivered before the ESS reaches end-of-life conditions (80\% of original capacity). Estimations of ESS degradation are adapted from 'Ah-throughput' battery and ultracapacitor aging models used in the analysis of hybrid buses by Orbaiz et al. and Carignano et al. [58,69]. The model assumes that the cooling of the ESS is sufficient so that any temperature effects on degradation are negligible. This approach avoids the use of arbitrary replacement number assumptions used in previous bus LCA studies [27,35,42,46,70], and improves upon previous life cycle energy throughput approaches $[11,43]$ by accounting for the ESS degradation influence of combined peak and off-peak periods, whilst factoring in the declining cost of future ESS replacements.

\subsubsection{Life Cycle Model}

For this framework, a hybrid-LCA approach is used with LCC calculations, covering an extensive system boundary, using process inputs (well-to-tank (WTT) and tank-to-wheel (TTW) emission factors, ESS manufacturing factors), and EIO-LCA inputs (vehicle manufacturing, infrastructure manufacturing and operation, and maintenance phases expressed as an amount of $\mathrm{CO}_{2} \mathrm{e}$ per unit cost from Harris et al. [43]). Bespoke EIO-LCA inputs are used in lieu of process-based manufacturing and maintenance data for selected bus technologies and charging infrastructure. Diesel refueling infrastructure is assumed to already be in place for ICE fleets.

TCO studies regularly neglect driver labour costs, despite wages often making up the majority of operational costs [71]. Studies that do consider driver labour costs either include wages within a lumped operational cost [20] or assume labour costs are equal for all technologies assessed and therefore exclude them from analysis $[11,24,25]$. However, with larger fleets, additional drivers are required, leading to more person-hours worked per day. This has been reflected in the life cycle model to ensure a fairer comparative assessment of fleets.

SCC is the monetary value of the damage done by emitting one tonne of carbon at a point in time, typically the present [72,73]. Uncertainties are present in SCC values, due to assumptions with modelling socioeconomic projections, anticipated climate responses, future benefits/damages and other economic factors [74]. A framework capable of probabilistic analysis is apt for including SCC in life cycle cost calculations. This study uses UK-based forecasts [75] and will assess if these values significantly affect TCO results.

Life cycle energy costs, WTW calculations and ESS replacement costs include forecasting factors, representing predicted annual changes of future energy and technology scenarios. A 3.5\% discount rate is applied the life cycle costing calculations [76] to represent costs in 2018 GBP values.

\subsection{Fleet Baseline}

The baseline in all scenarios was a single-deck conventional diesel fleet. All scenarios are simulated on the Route 159 service in London (a high passenger load, high frequency route in central London) (Error! Reference source not found.). Passenger data inputs for the fleet model were collected from Transport for London (TfL)

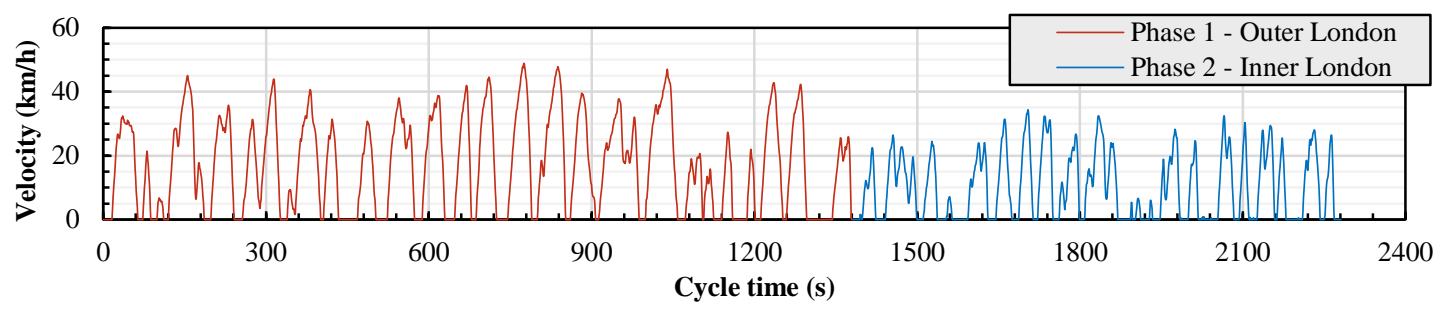

sources (Table 1).

Figure 3. Millbrook London Test Bus (MLTB) cycle data based on Route 159 in London [77].

Table 1. Data for London Route 159

\begin{tabular}{llll}
\hline & Peak & Off-peak & Daily \\
\hline Daily passengers $^{1}$ & 22061 & 4939 & 27000 \\
Hours in service $^{2}$ & $12(06: 00-18: 00)$ & $12(18: 00-06: 00)$ & 24 \\
Headway $(m i n)^{2}$ & 5 & 12 & - \\
Passengers per hour $^{2}$ & 1838 & 412 & 1125 \\
\hline
\end{tabular}




\footnotetext{
${ }^{1}$ Weekday passenger numbers obtained from a TfL press release [78] and percentage of peak/off-peak passenger numbers calculated as $82 \%$ to $18 \%$ from a TfL passenger survey [79].

${ }^{2}$ Based on timetable information from TfL [80].
}

\subsection{Technology Scenarios, Variables and Responses}

A technology scenario is defined as a group of variables with shape functions assigned to represent the probability of achieving certain values; 30 scenarios were assessed (Table 2). Single-deck (SD) and double-deck (DD) bodies were simulated for each scenario combination. Four ESS types were selected: three common lithiumion chemistries for heavy duty vehicle applications, lithium nickel-cobalt-manganese (NMC), lithium-iron phosphate (LFP) and lithium-titanate oxide (LTO), and an ultracapacitor (UC) used in the mild-hybrid drivetrain. A range of ESS technologies were simulated (i.e. not just individual battery packs of particular chemistries) to capture the general performance of ESS types in the design space. Charging infrastructure types refer to examples gathered from literature: $50 \mathrm{~kW}$ plug-in depot chargers [25], $50 \mathrm{~kW}$ opportunity inductive charging stations (Ind.) [81,82] and $300 \mathrm{~kW}$ opportunity conductive pantograph chargers (Con.) [83]. Model variables, shape functions and assumptions for each scenario are detailed in the Supplementary Material (Section S2).

Table 2. Overview of the 30 scenarios assessed.

\begin{tabular}{|c|c|c|c|c|c|c|c|c|c|}
\hline \multirow[b]{2}{*}{ Drivetrain } & \multicolumn{2}{|c|}{ Body } & \multicolumn{4}{|l|}{ ESS } & \multicolumn{3}{|c|}{ Charging infrastructure } \\
\hline & $\mathrm{SD}$ & $\mathrm{DD}$ & NMC & LFP & LTO & $\mathrm{UC}$ & Plug-in & Inductive (Ind.) & Conductive (Con.) \\
\hline Diesel & $\checkmark$ & $\checkmark$ & & & & & & & \\
\hline Micro-hybrid & $\checkmark$ & $\checkmark$ & & & & & & & \\
\hline Mild-hybrid & $\checkmark$ & $\checkmark$ & $\checkmark$ & $\checkmark$ & $\checkmark$ & $\checkmark$ & & & \\
\hline BEB (depot) & $\checkmark$ & $\checkmark$ & $\checkmark$ & $\checkmark$ & $\checkmark$ & & $\checkmark$ & & \\
\hline BEB (opp) & $\checkmark$ & $\checkmark$ & $\checkmark$ & $\checkmark$ & $\checkmark$ & & $\checkmark^{1}$ & $\checkmark$ & $\checkmark$ \\
\hline
\end{tabular}

\subsection{Probabilistic Assessment}

Monte Carlo simulation, a probabilistic technique that uses repeated random sampling of variables to obtain numerical results, was used for the probabilistic assessment step. Parameters and assumptions for the probability shape functions used in each scenario are detailed in Supplementary Material (Section S2). For each scenario, 5000 Monte Carlo iterations were executed. Life cycle results are presented as cumulative distribution function (CDF) plots, displaying the percentage deviations from the baseline result. CDF plots can be interpreted as 'what result could happen' along the $\mathrm{x}$-axis and 'the risk/probability of that result occurring' along the y-axis. For the results, two probability levels were selected: a $20 \%$ probability is interpreted as a high risk probability level, where an $80 \%$ probability is seen as an acceptable low risk probability level for decision makers $[43,44,84,85]$. 


\section{Results}

\subsection{Baseline and Key Fleet Results}

The baseline results for TCO, life cycle GHG emissions (LC-GHG) and other key performance metrics of the SD diesel fleet were calculated in the model, using central fixed estimates for all forecast parameters (Tables 3 - 5). Probabilistic SD diesel fleet results are also presented to show the influence of these forecast parameters (e.g. fuel costs). Although the framework used 2018 equivalent GBP cost inputs, results have been converted to 2018 equivalent Euros at the exchange rate of 1.135 euro per GBP [86].

Table 3. Baseline single-deck diesel fleet and average individual vehicle TCO results.

\begin{tabular}{llllllll}
\hline & $\begin{array}{l}\text { Capital } \\
(2018 €)\end{array}$ & $\begin{array}{l}\text { Fuel } \\
(2018 €)\end{array}$ & $\begin{array}{l}\text { Maintenance } \\
(2018 €)\end{array}$ & $\begin{array}{l}\text { ESS } \\
(2018 €)\end{array}$ & $\begin{array}{l}\text { Infrastructure } \\
(2018 €)\end{array}$ & $\begin{array}{l}\text { Driver labour } \\
(2018 €)\end{array}$ & $\begin{array}{l}\text { SCC } \\
(2018 €)\end{array}$ \\
\hline Per fleet & $5,163,314$ & $8,966,311$ & $4,062,115$ & - & 34,166 & $67,119,507$ & 63,626 \\
Per vehicle & 139,549 & 242,332 & 109,786 & - & 922 & $1,814,039$ & 1,718 \\
\hline
\end{tabular}

Table 4. Baseline single-deck diesel fleet and average individual vehicle LC-GHG results.

\begin{tabular}{|c|c|c|c|c|c|c|c|}
\hline & $\begin{array}{l}\text { Manufacture } \\
\left(\mathrm{kgCO}_{2} \mathrm{e}\right)\end{array}$ & $\begin{array}{l}\text { WTT } \\
\left(\mathrm{kgCO}_{2} \mathrm{e}\right)\end{array}$ & $\begin{array}{l}\text { TTW } \\
\left(\mathrm{kgCO}_{2} \mathrm{e}\right)\end{array}$ & $\begin{array}{l}\text { Maintenance } \\
\left(\mathrm{kgCO}_{2} \mathrm{e}\right)\end{array}$ & $\begin{array}{l}\text { ESS } \\
\left(\mathrm{kgCO}_{2} \mathrm{e}\right)\end{array}$ & $\begin{array}{l}\text { Infrastructure } \\
\left(\mathrm{kgCO}_{2} \mathrm{e}\right)\end{array}$ & $\begin{array}{l}\text { LC-GHG } \\
\left(\mathrm{kgCO}_{2} \mathrm{e}\right)\end{array}$ \\
\hline Per fleet & $2,868,586$ & $3,698,306$ & $18,271,246$ & 726,771 & 0 & 6,756 & $25,571,666$ \\
\hline Per vehicle & 77,529 & 99,954 & 493,817 & 19,643 & 0 & 183 & 691,127 \\
\hline
\end{tabular}

Table 5. Other performance metrics for the baseline single deck diesel fleet and average vehicle.

\begin{tabular}{llllll}
\hline $\begin{array}{l}\text { Operation } \\
\text { Period }\end{array}$ & $\begin{array}{l}\text { Vehicle energy } \\
\text { consumption per km } \\
(\mathrm{kWh} / \mathrm{km})\end{array}$ & $\begin{array}{l}\text { Daily } \\
\text { distance } \\
(\mathrm{km})\end{array}$ & $\begin{array}{l}\text { Vehicles needed to } \\
\text { satisfy frequency }\end{array}$ & $\begin{array}{l}\text { Additional vehicles } \\
\text { needed to satisfy } \\
\text { capacity }\end{array}$ & $\begin{array}{l}\text { Additional vehicles } \\
\text { needed to satisfy daily } \\
\text { range }\end{array}$ \\
\hline Peak & 2.96 & 111.4 & 18 & 11 & $\begin{array}{l}\text { Total } \\
\text { fleet } \\
\text { size }\end{array}$ \\
Off-peak & 2.88 & 28.8 & 8 & 0 & 3 \\
\hline
\end{tabular}

The minimum fleet size required to fulfil the daily service was calculated based on a bus fleet's ability to satisfy the peak period frequency and capacity as well as the range capability (Figure 4Error! Reference source not found.). The fleet size required to satisfy a peak headway of 5 minutes is independent of the technological capability of the bus and is the same in all scenarios (for a 2-way route). Fewer DD vehicles are required to satisify peak capacity than for SD fleets. ESS capacity is insufficient to fulfil the daily service for the opportunity inductively charged and the depot plug-in BEB fleets and therefore larger fleets are required to meet all demands, except for the SD NMC BEB fleet. 
Figure 4. Fleet size for each scenario for the $80 \%$ probability level.

Vehicle range influences the total distance travelled by the average vehicle in a given fleet (Figure

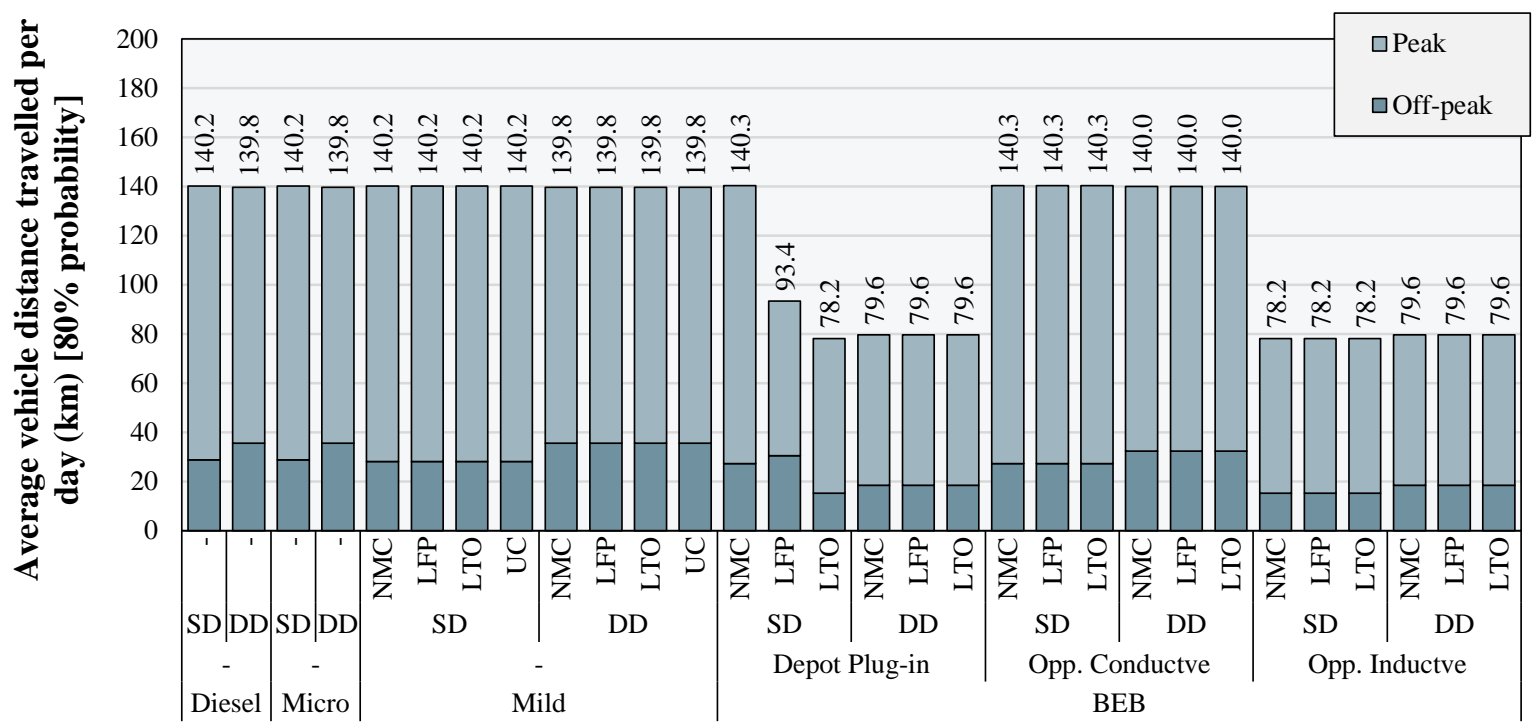

5Error! Reference source not found.); larger fleets result in lower average daily distances. Daily ICE fleet distances are virtually identical, indicating that more SD buses required in the fleet provide a more frequent service, but are less efficiently utilized than DD variants.

Figure 5. Daily distance travelled by the average vehicle in each fleet scenario ( $80 \%$ probability).

At high probability conditions for every scenario, energy consumption per km is higher under peak conditions than off-peak due to the increased passenger loading (Figure 6). SD opportunity NMC fleets are the most energy efficient with a small battery mass and efficient electrical drivetrain. Engine stop-start

and smart auxiliaries result in a $16 \%$ to $20 \%$ fuel consumption reduction in micro-hybrid vehicles compared to conventional Euro VI vehicles. $31 \%$ to $36 \%$ fuel consumption reductions are possible with battery powered mild-hybrid fleets, but the UC configurations only show $27 \%$ to $30 \%$ reductions. This can be attributed to low UC capacity leading to fewer opportunities for electrical deployment. SD vehicles are typically more energy efficient than their DD counterparts, except for the SD depot plug-in BEBs (due to the larger ESS pack sizing, discussed in detail in section 3.3).Figure 6. Energy consumption per km of the average vehicle in each fleet scenario ( $80 \%$ probability).

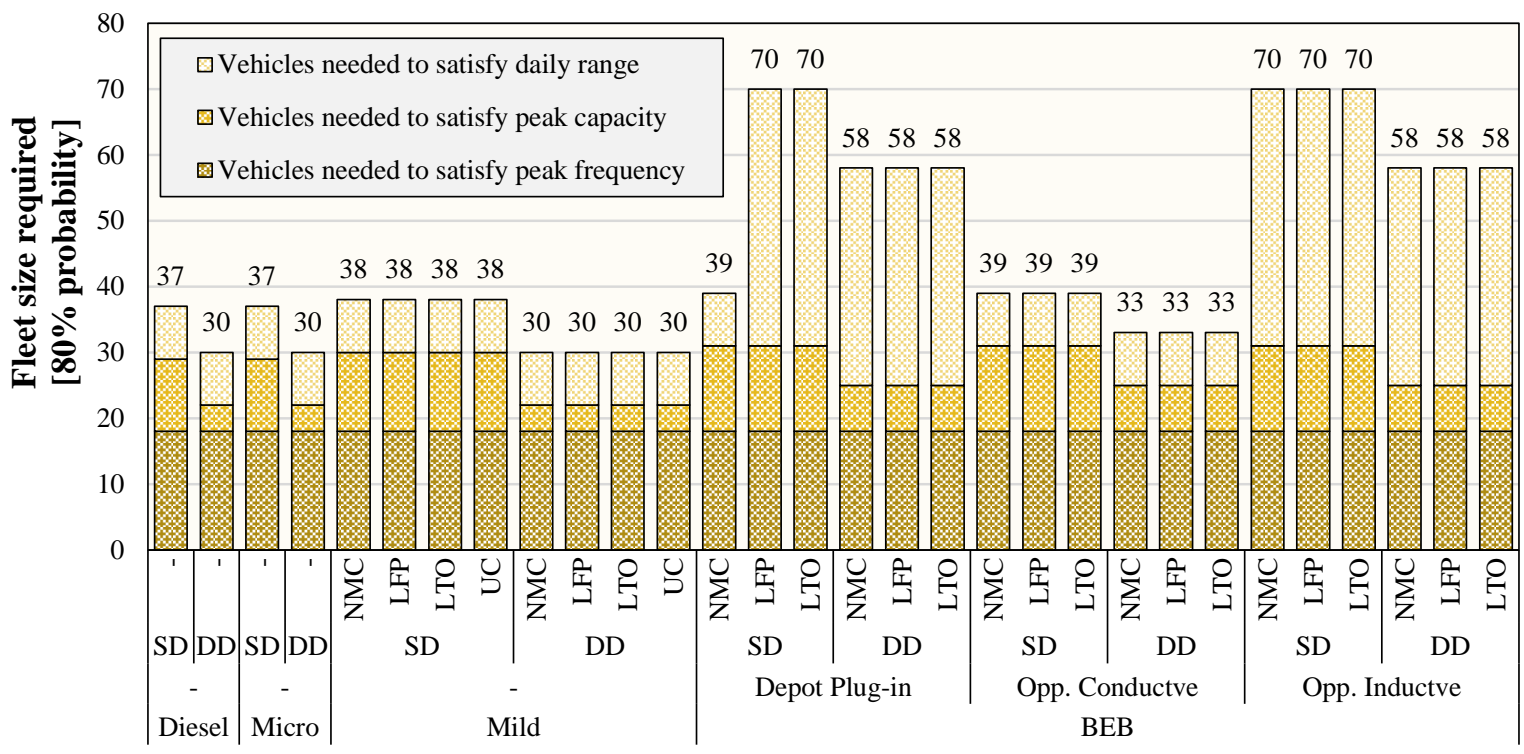




\subsection{ICE Fleet Results}

ICE fleet probabilistic results for TCO (Figure 7) and LC-GHG (Figure 8Error! Reference source not found.) are presented in this section.
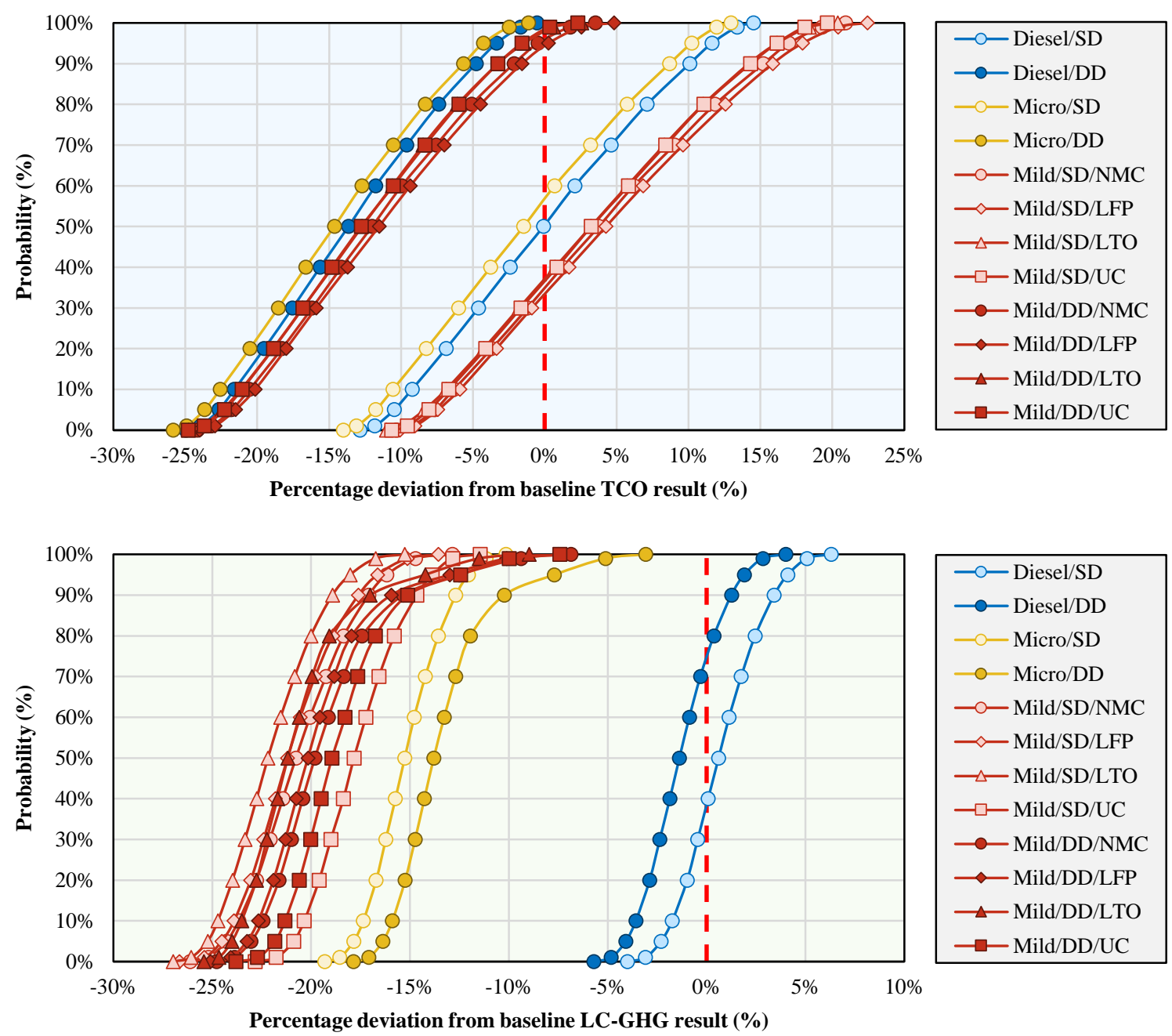

Figure 7 TCO CDF plots for ICE fleets represented as \% deviations from baseline diesel SD fleet.

Figure 8 LC-GHG CDF plots for ICE fleets represented as \% deviations from baseline diesel SD fleet.

For all probability levels, the micro-hybrid DD fleet has the lowest TCO, followed closely by the conventional diesel DD fleet (Figure 7). For mild-hybrid fleets, the UC configuration is the cheapest at all probability levels. All DD mild-hybrid fleets are significantly cheaper than their single deck counterparts, due to the increased passenger capacity and fewer vehicles needed.

LC-GHG results show that the mild-hybrid fleets produce the lowest GHG emissions. SD mild hybrids equipped with a LTO ESS are the cleanest option for all probability levels (Figure 8Error! Reference source not found.). Battery systems in the mild hybrids have lower LC-GHG than the ultracapacitor configurations, with the LTO ranking first followed by LFP and then NMC for both body types. At all probability levels, micro-hybrid fleets show lower LC-GHG results than the baseline. There is a 77\% probability that the DD diesel fleet has a lower LC-GHG than the baseline.

At the $80 \%$ probability level, the TCO of ICE fleets is dominated by driver labour costs, ranging between $73 \%$ and $81 \%$ of a fleet's TCO (Figure 9a). With fewer DD buses needed than SDs to complete the daily service (Figure 4Error! Reference source not found.), fewer person-hours are required. Labour costs are therefore lower and for all ICE fleets, DD bus fleets are cheaper than their SD counterparts. Capital and maintenance costs tend to increase with hybridization and are higher than the lifetime fuel cost for all mild hybrid fleets. LFP batteries are the most expensive ESS replacement in all mild-hybrid fleets, with the cheapest being the UC system (Figure 
10). The SCC and infrastructure phases combined contribute $<1 \%$ of the TCO in all fleet scenarios. SCC results do not add a significant amount to TCO totals, potentially indicating that the UK forecast values used are very low.

The TTW phase of the ICE fleets is the highest contributor to GHG emissions in all scenarios (Figure 9b). WTT emissions are the second highest in both diesel scenarios and the SD micro-hybrid fleet, but are surpassed by manufacturing GHG emissions for the DD micro-hybrid and all mild-hybrid fleets. Increased hybridization leads to a higher proportion of GHG emissions resulting from ICE fleet maintenance, but is only the fourth most damaging phase for all ICE scenarios. The high number of charge-discharge cycles of ultracapacitor configurations results in the lowest GHG emissions from ESS replacements in the mild hybrid fleets (Figure 10). Infrastructure GHG emissions are negligible ( $<0.03 \%$ of the LC-GHG in all scenarios).

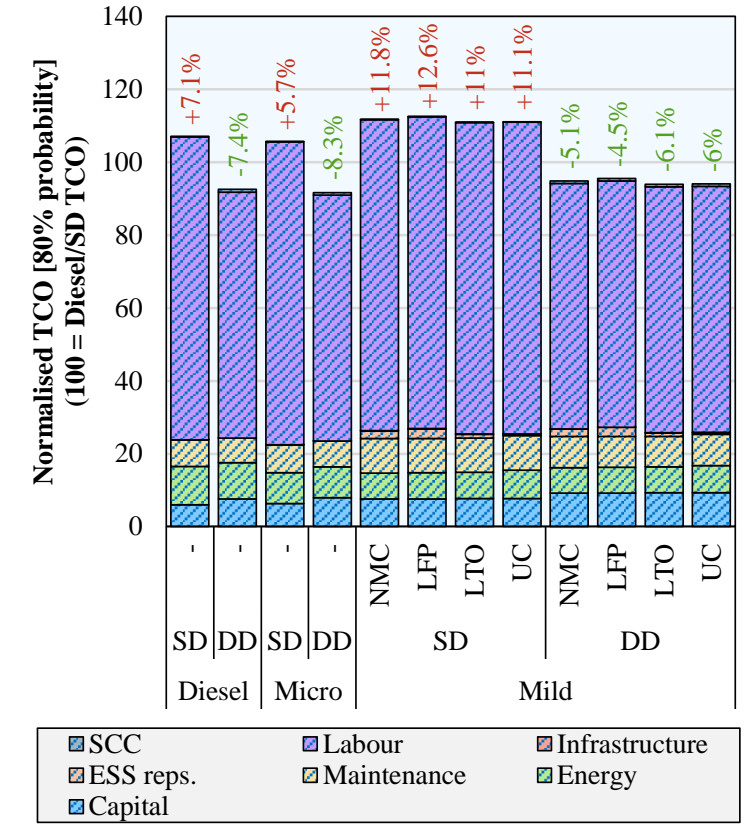

(a)

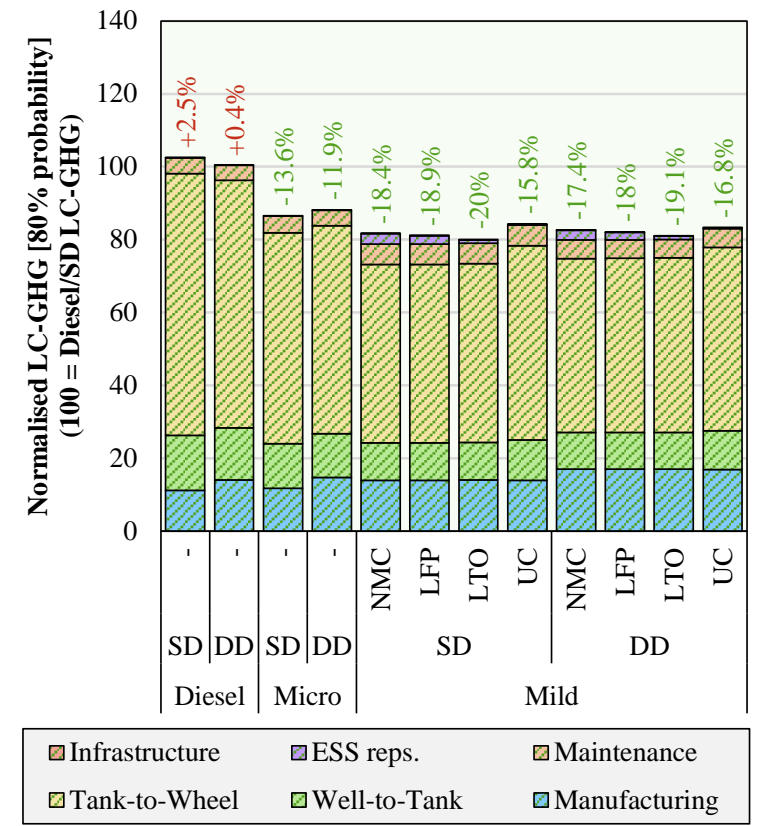

(b)

Figure 9 Normalized 80\% probability results for ICE fleets (a) TCO and; (b) LC-GHG. Note that probabilistic SD diesel results are also presented against the deterministic SD diesel fleet baseline.

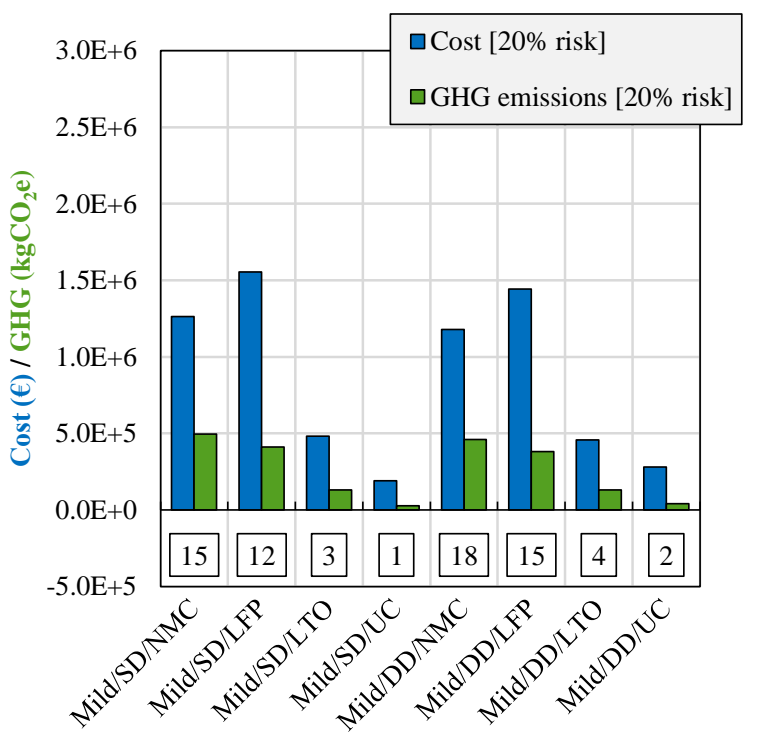

(a)

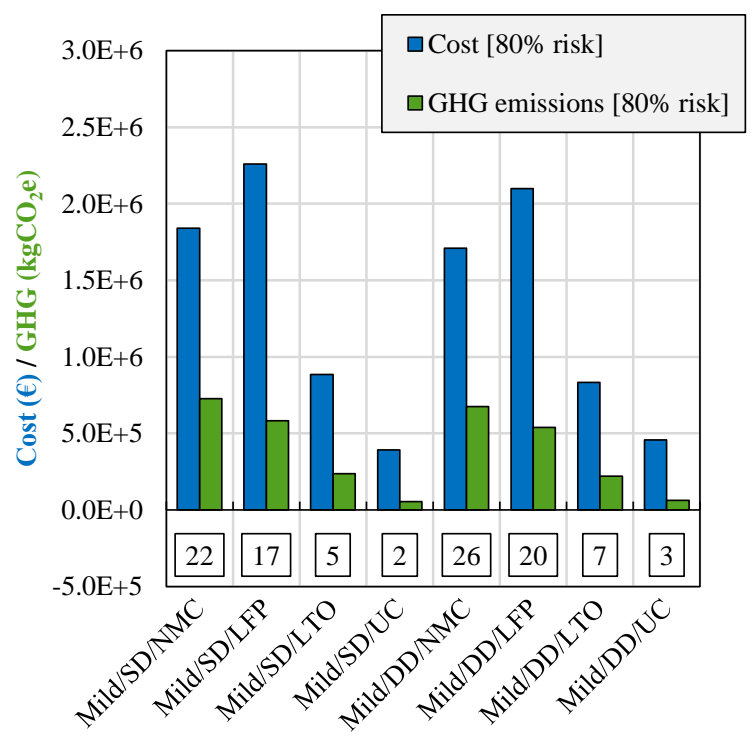

(b) 
Figure 10 Mild hybrid fleet ESS results for (a) 20\% probability level and; (b) $80 \%$ probability level. Note the figure in the square indicates

the number of ESS replacements per vehicle in the life cycle.

\subsection{BEB Fleet Results}

BEB fleet probabilistic results for of TCO (Figure 11) and LC-GHG (Figure 12Error! Reference source not found.) results are presented as percentage deviations from the baseline SD diesel fleet results.
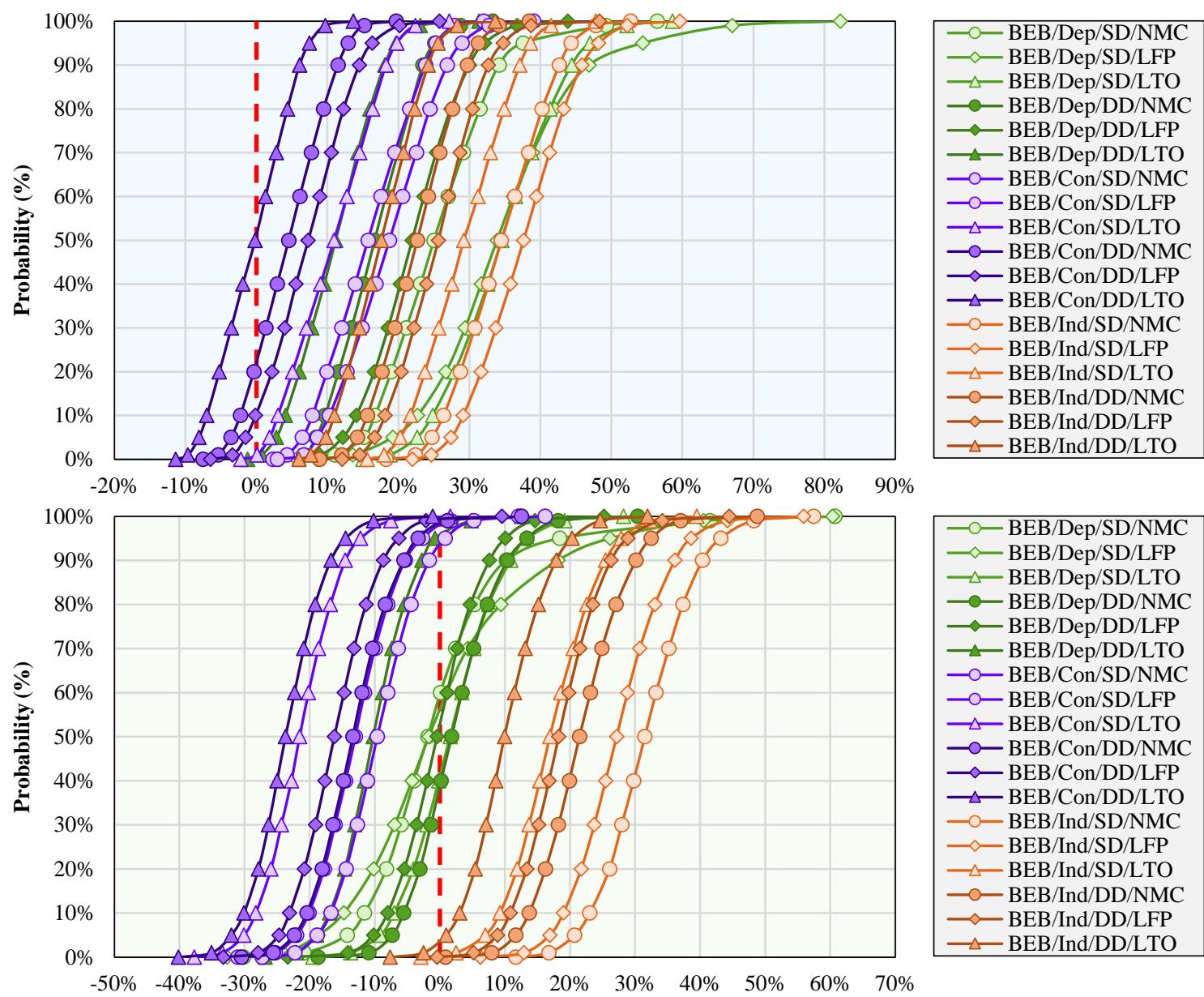

Percentage deviation from baseline LC-GHG result $(\%)$

Figure 11. TCO CDF plots for BEB fleets represented as \% deviations from baseline diesel SD fleet.

Figure 12. LC-GHG CDF plots for BEB fleets represented as \% deviations from baseline diesel SD fleet.

TCO results reveal that the DD conductively charged BEB fleet equipped with a LTO ESS has the lowest TCO of the BEB scenarios at all probability levels (Figure 11). However, there is only a 50\% probability that this fleet will have equal or lower TCO than the baseline SD diesel fleet. Other BEB fleets show this, notably the DD conductively charged NMC and LFP BEB fleets, but the probability of TCO being equal or less than the baseline is only $20 \%$ and $10 \%$ respectively. Regardless of charging option or ESS type, DD body configurations tend to be cheaper than SD counterparts. In all body and charging scenarios, the LTO ESS is the lowest TCO option.

There is a $94 \%$ probability that all conductively charged BEB fleets will have an equal or lower LC-GHG than the SD diesel baseline, with the LTO DD configuration being the lowest (Figure 12Error! Reference source not found.). For the opportunity-charged fleets (conductive and inductive), the body configuration selection is significant, as DD bodies have lower LC-GHG than the SD bodies. However, when considering the depot-charged BEB fleets, at the lower probability levels SD fleets tend to have lower LC-GHG than DD fleets, but at higher probabilities there is no LC-GHG saving, except for the DD LTO BEB fleet. 
Like the ICE fleets, driver labour costs dominate the BEB fleet TCO, making up 56 to $74 \%$ of TCO (Figure 13a). ESS size and type is significant; for all NMC and LFP fleets, ESS replacement costs are greater than life cycle energy costs. LTO scenarios have a lower available capacity due to mass restrictions and a lower energy density, with opportunity ESS packs having a smaller capacity than the depot charge scenarios (Figure 14). Due to lower life cycle distances covered by individual LTO depot-charged vehicles (Figure 5Error! Reference source not found.), no ESS replacement is required (Figure 15), indicating a trade-off between fleet size (and fleet capital) and ESS replacement costs. For all opportunity charging scenarios, LTO fleets have the highest capital cost, but the lowest ESS replacement and TCO costs over other chemistries. This is consistent even when excluding driver labour costs.

Manufacturing and WTT phases are the highest contributors to LC-GHG of BEB fleets (Figure 13b). ESS capacity and chemistry selection have a significant influence on LC-GHG emission results; high charge-discharge cycles of LTO batteries offset high manufacturing GHG emissions by reducing ESS replacement impacts (Figure 15) and ultimately LC-GHG. The lower mass of opportunity BEBs results in lower energy consumption and lower WTT emissions than depot charging scenarios. Selection of charging infrastructure significantly influences fleet LC-GHG (and TCO); plug-in depot chargers have the lowest manufacturing, installation and O\&M costs and GHG emissions, followed by the conductive infrastructure (Figure 16). Inductive chargers by themselves are unable to sustain the fleet opportunity recharging requirements, hence additional depot chargers are needed to ensure fulfillment of passenger service, significantly driving up costs and GHG emissions (Figure 16). Fewer vehicles to recharge (i.e. DD fleets) results in fewer charge points. Increasing vehicle range and improving fleet scheduling is key to lowering TCO and LC-GHG.

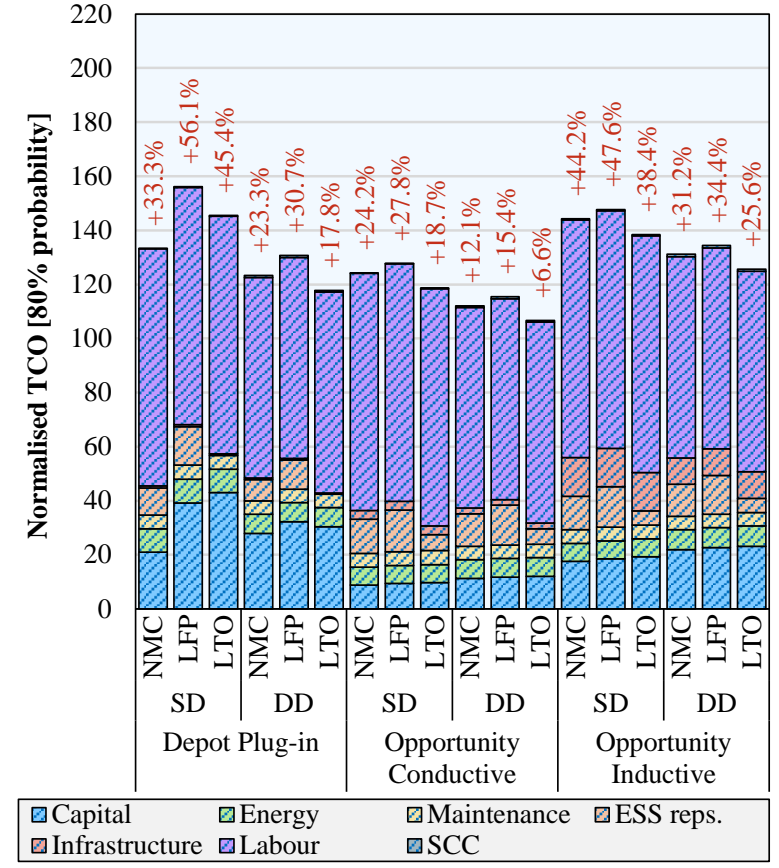

(a)

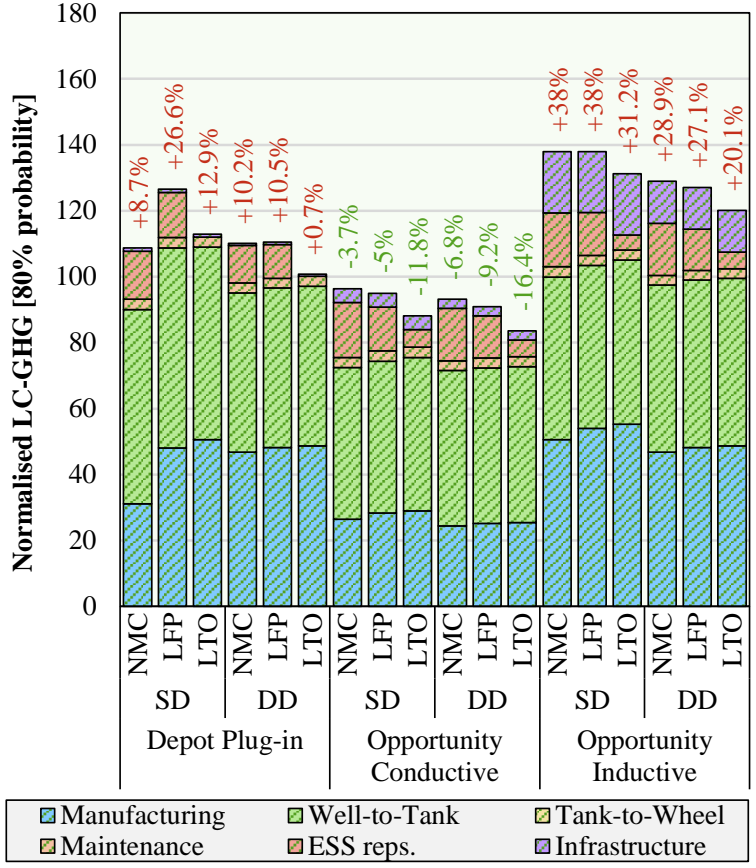

(b)

Figure 13 Normalized 80\% probability results for BEB fleets (a) TCO and; (b) LC-GHG. Note that 100 on the y-axis represents the baseline SD diesel fleet result. 

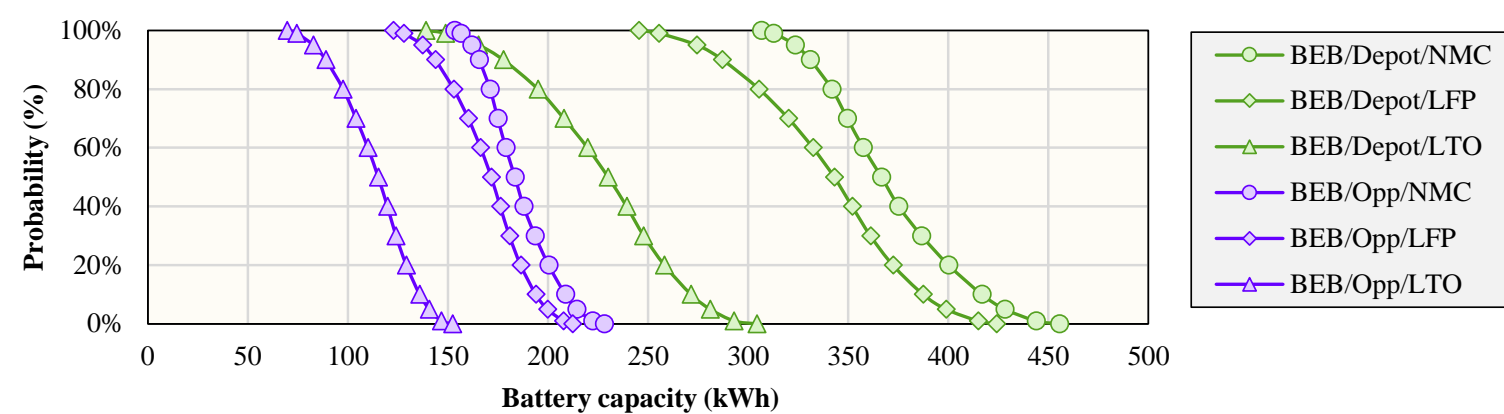

Figure $14 \mathrm{CDF}$ plots of the probable battery capacity for depot and opportunity charged BEB fleets accounting for ESS energy density and not exceeding the legal maximum GVW of 19.5 tonnes.
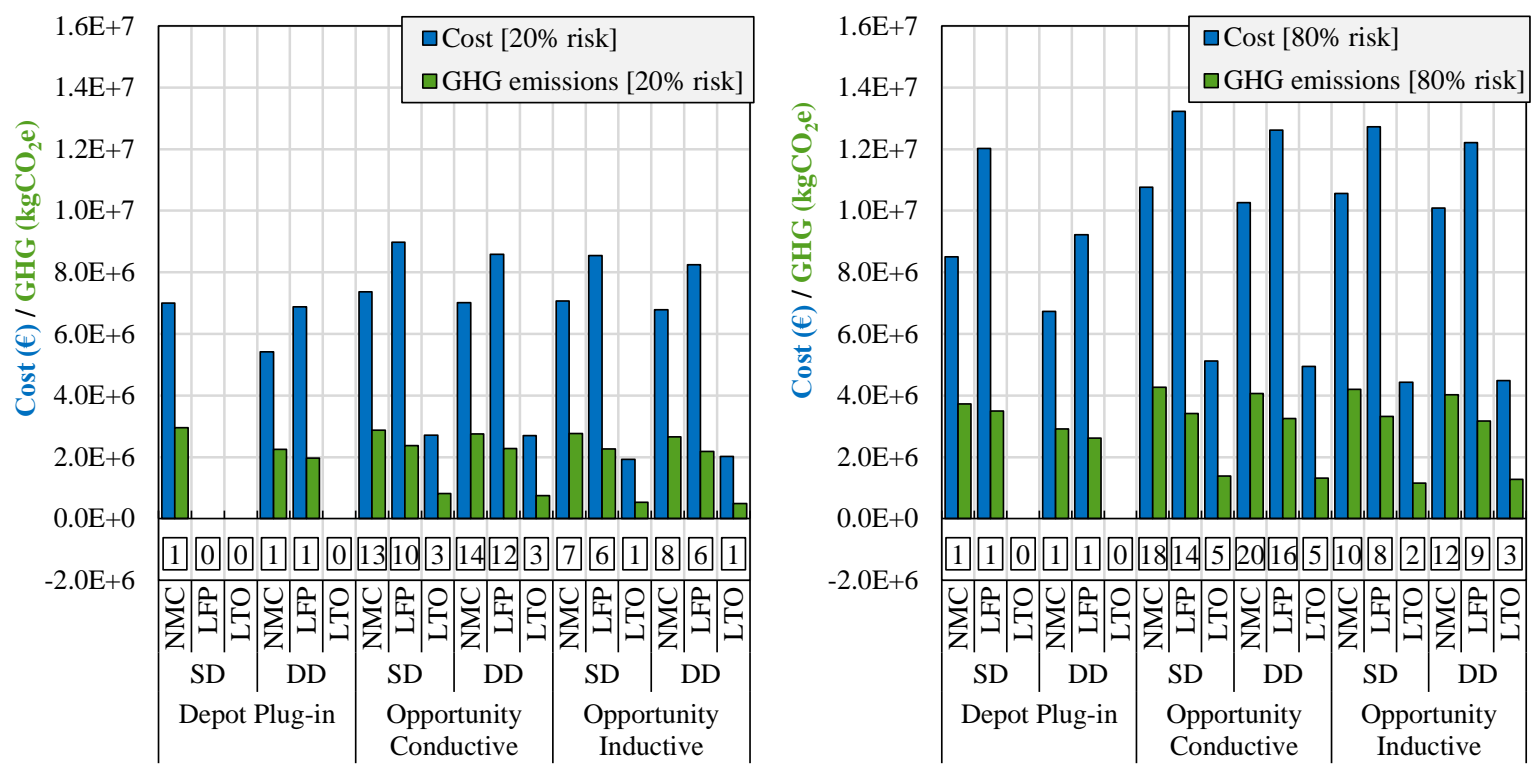

(a)

(b)

Figure 15 BEB fleet ESS results for (a) 20\% probability level and; (b) $80 \%$ probability level. Note the figure in the square indicates the number of ESS replacements per vehicle in the life cycle.

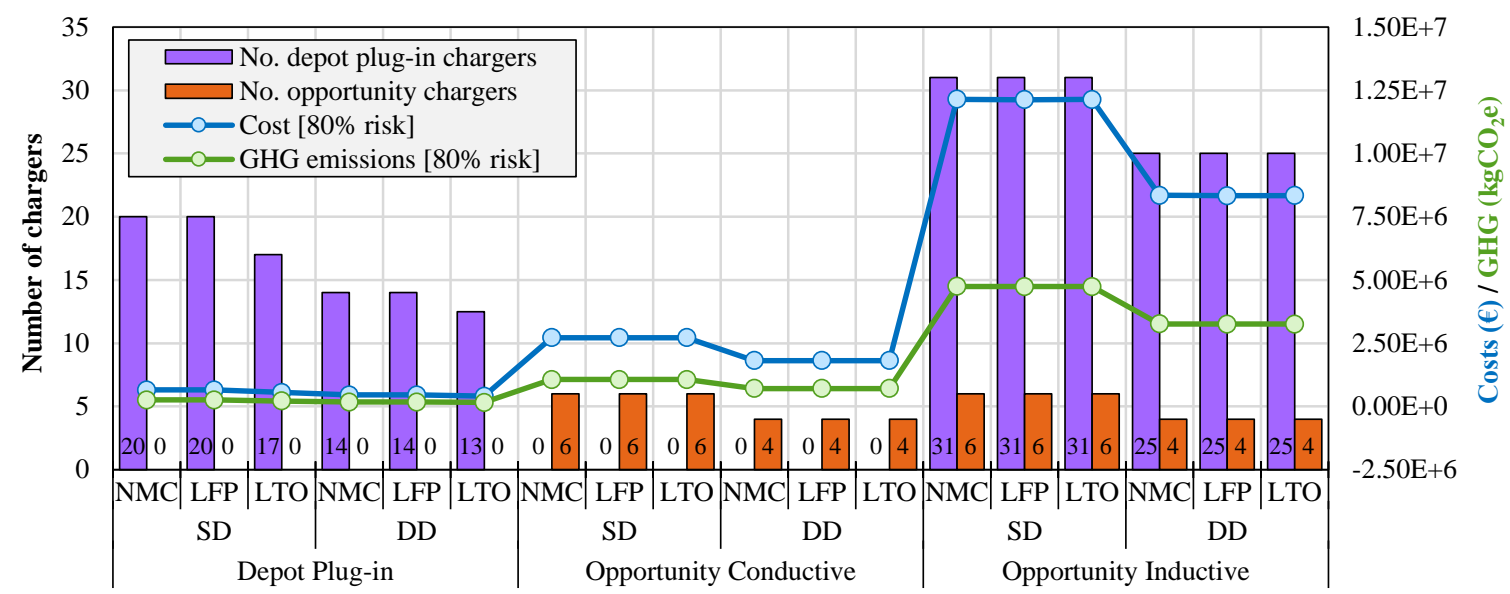

Figure 16. Charging infrastructure stations required for each BEB scenario and corresponding cost and GHG emissions at the $80 \%$ probability level. 


\subsection{Cost effectiveness}

For the $80 \%$ probability level, no scenarios provide capital cost savings over the baseline diesel SD fleet, but the most cost effective is the SD micro-hybrid fleet which mitigates $1 \mathrm{~kg} \mathrm{CO}_{2} \mathrm{e}$ per $0.07 \mathrm{GBP}$ of additional capital cost to the operator (Figure 17Error! Reference source not found.). The equivalent additional cost for the mildhybrid scenarios is an additional 0.24 to 0.32 GBP for SD fleets and 0.52-0.57 GBP for DD fleets to mitigate 1 $\mathrm{kg} \mathrm{CO}$ e. Conductive charging of BEB fleets would mitigate LC-GHG at an additional capital cost of between 0.65 and $1.89 \mathrm{GBP}$ per $\mathrm{kg} \mathrm{CO}_{2}$ e mitigated. If infrastructure capital were to be considered, this value would increase significantly.

All mild-hybrid DD fleets reduce TCO and LC-GHG for the $80 \%$ probability level (Figure 18), with the UC DD mild-hybrid fleet showing the maximum TCO saving of 1.05 GBP for every $\mathrm{kgCO}_{2} \mathrm{e}$ mitigated in the life cycle. However, overall the DD micro-hybrid fleet has the best saving, with 2.05 GBP of TCO saved for every $\mathrm{kgCO}_{2} \mathrm{e}$ mitigated in the life cycle. The most cost effective zero tailpipe emission fleet is the conductive DD LTO $\mathrm{BEB}$, costing an additional $0.67 \mathrm{GBP}$ of TCO per $\mathrm{kgCO}_{2} \mathrm{e}$ mitigated. DD fleets tend to be more cost-effective at mitigating LC-GHG than SD counterparts.

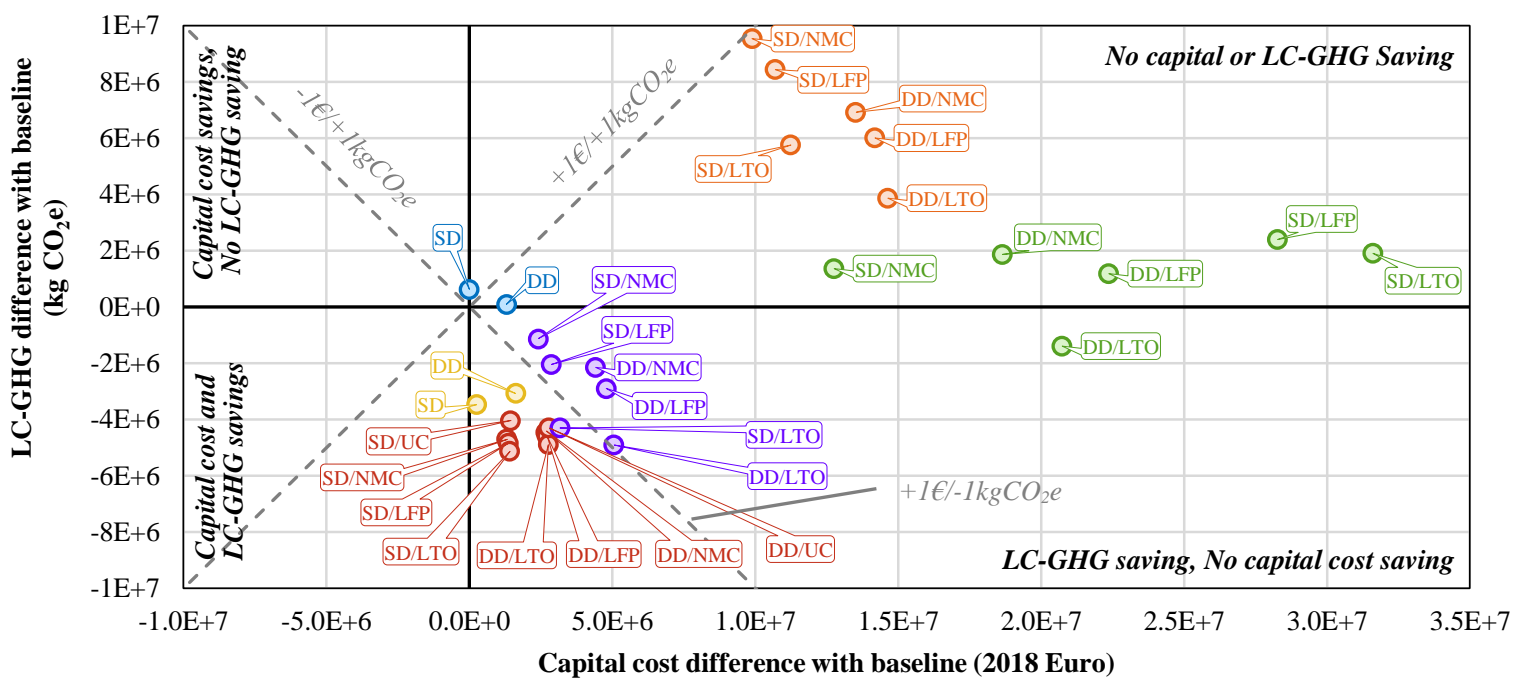

oDiesel OMicro-hybrid OMild-hybrid OBEB (Depot plug-in) o BEB (Opp. Conductive) OBEB (Opp. Inductive)

Figure 17. Cost effectiveness of mitigating LC-GHG per additional fleet capital ( $80 \%$ probability).

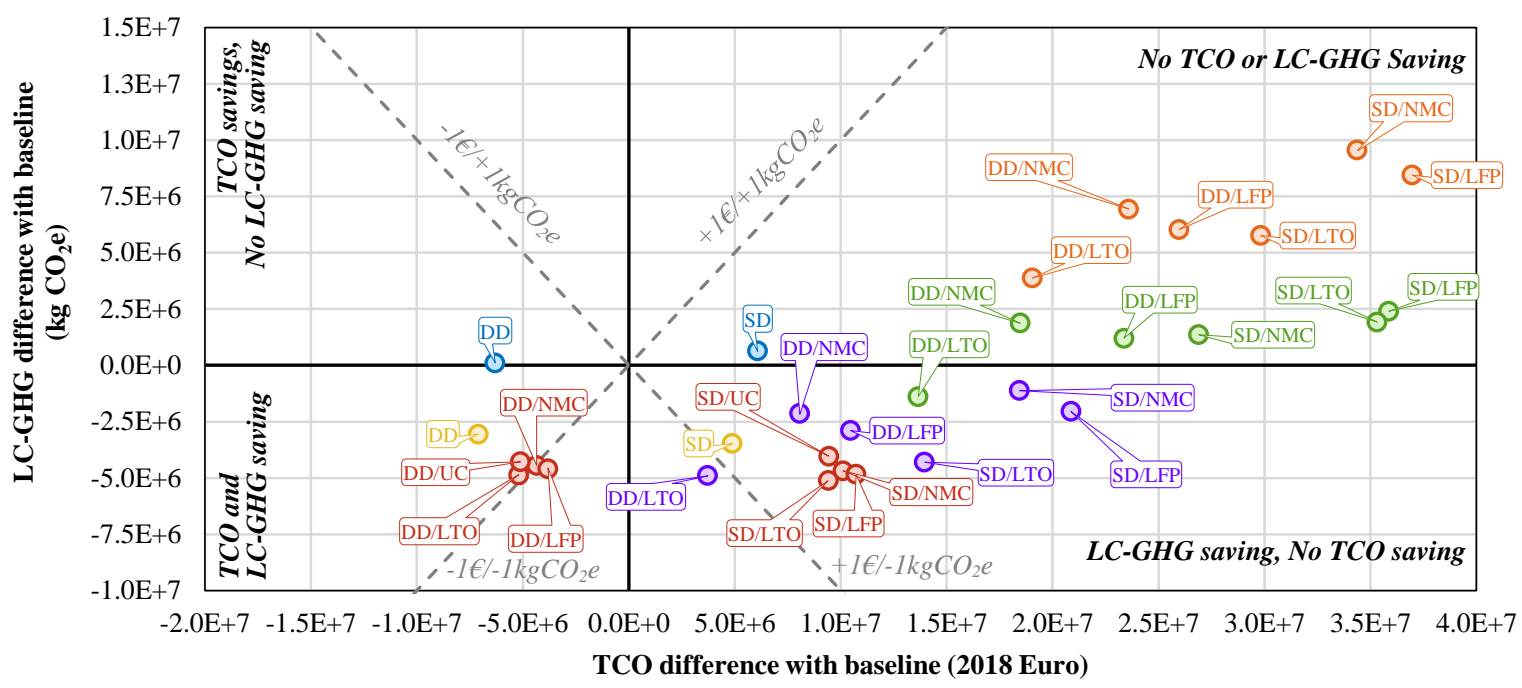

oDiesel OMicro-hybrid OMild-hybrid OBEB (Depot plug-in) OBEB (Opp. Conductive) OBEB (Opp. Inductive)

Figure 18. Cost effectiveness of mitigating LC-GHG per additional fleet TCO (80\% probability). 


\subsection{Fleet-By-Fleet vs.Vehicle-By-Vehicle Analysis Results}

In the paper thus far, results have been presented on the fleet level. To show the significance of fleet analysis, the model was rerun to examine the TCO and LC-GHG impacts of switching from a traditional vehicle-by-vehicle comparison (Figure 19). TCO comparisons show that for the ICE scenarios, a vehicle-by-vehicle analysis results in cost savings for the SD vehicles over the baseline, with DD vehicles displaying higher TCO than the baseline for $20 \%$ and $80 \%$ probability levels (Figure 19). However, when viewed from the fleet perspective, DD ICE fleets reveal greater TCO savings benefits than SD equivalent fleets. For the depot plug-in and conductive opportunity charge BEB scenarios, vehicle-by-vehicle comparisons indicate lower TCO increases over the baseline for the SD vehicles. The opposite is true for the fleet-by-fleet comparison where DD fleets show lower increases in TCO (at both probability levels). For the inductively charged BEB scenarios, the vehicle-by-vehicle analysis indicates a lower increase in TCO than a fleet-by-fleet comparison, regardless of body type.

For the $20 \%$ and $80 \%$ probability levels, LC-GHG comparisons show a similar trend to the TCO results; LC-GHG savings are greater for SD vehicles when using a vehicle-by-vehicle comparison, but if a fleet-by-fleet analysis is conducted, DD vehicles show the greater reductions over a baseline diesel fleet (Figure 19). For all BEB scenarios, except the conductively charged LTO BEB, LC-GHG savings are observed to be lower when conducting a fleet comparison over a vehicle-by-vehicle comparison (at both probability levels).

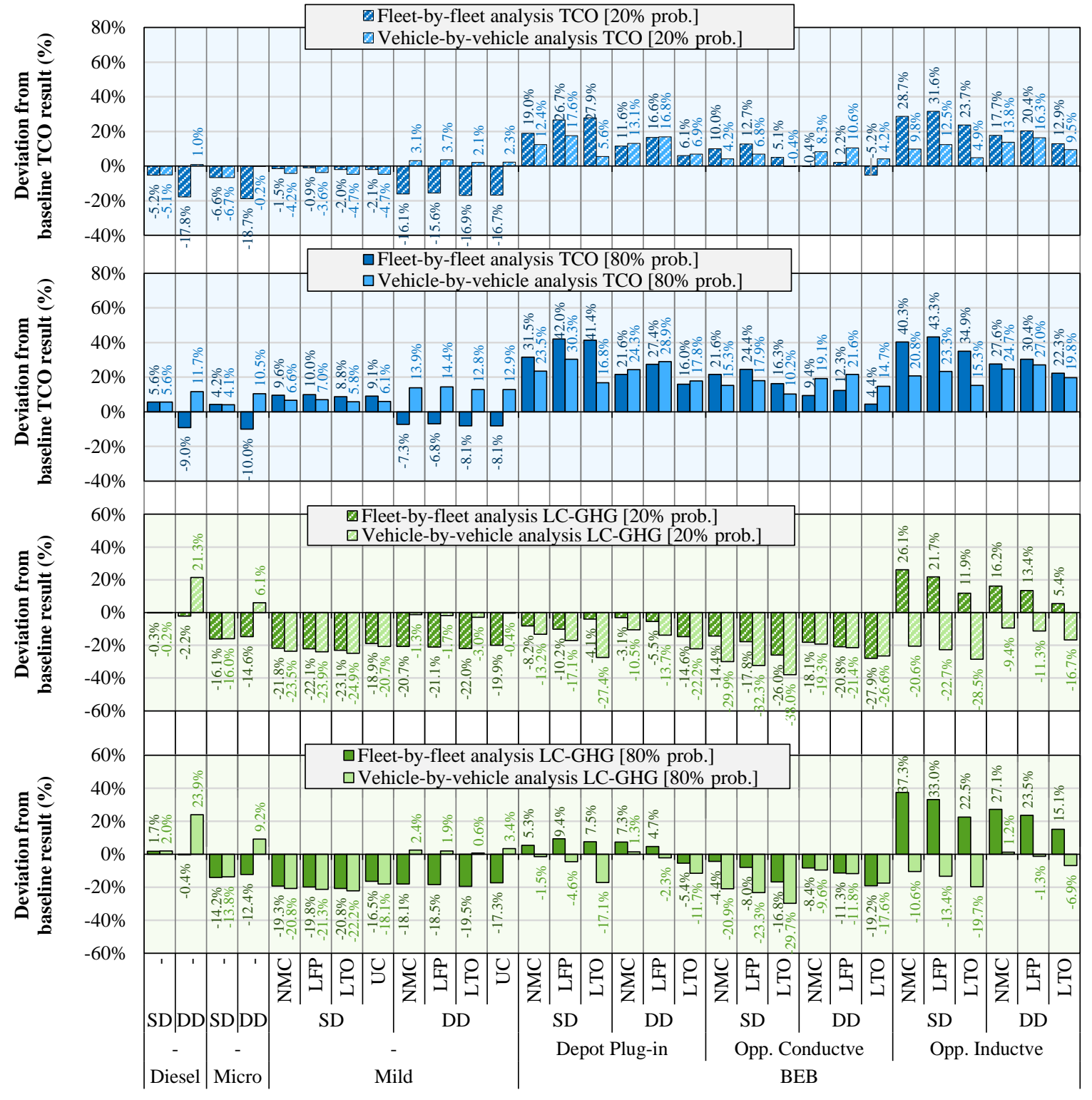

Figure 19 Fleet comparison and vehicle comparison results for TCO and LC-GHG represented as deviations from the baseline SD diesel fleet or vehicle result (see Table $3 \& 4$ ). 


\section{Discussion}

\subsection{Using the Framework to Support Decision Making}

The framework developed in this study provides a novel and unique capability to simultaneously assess the performance of multiple bus technologies over a designated route, providing quantifiable fleet-wide life cycle cost and GHG emissions results. The framework enables insight into the life cycle trade-offs between passenger capacity, charging infrastructure type and placement and the minimum fleet size required, further influencing vehicle life cycle distance covered, ESS replacements, as well as acquisition costs and manufacturing impacts.

For the high capacity urban case study presented, the micro-hybrid DD fleet had the lowest TCO of all scenarios at all probability levels (Table 6). At the high risk, 20\% probability level, the conductively charged DD BEB fleet with a LTO ESS had the lowest LC-GHG. At the lower risk, $80 \%$ probability level, the SD LTO mildhybrid fleet shows the lowest LC-GHG. A new technology's ability to mitigate LC-GHG whilst reducing the risk of potential TCO increases (or even saving costs) would boost the financial case for alternative drivelines. Examining results from a 'cost-effectiveness' perspective provides a useful metric to evaluate combined TCO and LC-GHG impacts, but micro and mild-hybrids are shown to be more cost-effective at reducing LC-GHG.

Table 6. Qualitative results for the best option for lowest TCO and LC-GHG.

\begin{tabular}{lll}
\hline Life Cycle Metric (analysis type) & $20 \%$ probability & $80 \%$ probability \\
\hline Lowest TCO (by fleet analysis) & Micro/DD & Micro/DD \\
Lowest TCO (by vehicle analysis) & Micro/SD & Micro/SD \\
Lowest LC-GHG (by fleet analysis) & BEB/Con/DD/LTO & Mild/SD/LTO \\
Lowest LC-GHG (by vehicle analysis) & BEB/Con/SD/LTO & BEB/Con/SD/LTO
\end{tabular}

Driver labour costs are the largest cost component of TCO in all scenarios, being highly sensitive to fleet size. This factor can be offset by examining the cost-benefit of passenger fare revenue; a recent study has shown that passengers are willing to pay extra for a service that improves air quality and alleviates energy security concerns [87]. Additional subsidies towards acquisition and operational costs can increase the cost-effectiveness of BEB fleets, but the framework can also inform manufacturers of areas to help improve life cycle costeffectiveness beyond capital investment.

These results demonstrate the risk and uncertainty assessment capability within the framework and how it can inform the decision-making process for the procurement of new fleets, but the potential impacts beyond the model capabilities should also be taken in account. Reducing fuel consumption is paramount for decreasing GHG emissions and operational costs, but needs to be combined with high adoption of alternative technologies to bring about significant reductions [12]. However, the introduction of clean air strategies in cities (e.g. ultra-low emission zones [88]), means that ICE-based technologies cannot be the long-term solution. For instance, newly procured SD fleets in central London from 2020 must have zero exhaust emissions [89]. This immediately excludes all SD ICE fleet scenarios evaluated. Future framework iterations should consider local air quality impacts and other environmental impact categories and other zero tailpipe emission capable technologies, e.g. hydrogen fuel cell.

Wider context and acknowledgement of all stakeholder concerns and inputs should be considered when using the framework. For example, conductive charging of BEBs provides lowest TCO and LC-GHG of the BEB scenarios evaluated. However, consideration would have to be given to route spatial constraints and the feasibility of installing pantograph chargers in a densely populated urban area. The impact on other road traffic and cosharing benefits, e.g. permitting other heavy-duty vehicles to use high voltage chargers to alleviate local air quality concerns and generate additional revenue for the bus operator.

\subsection{Fleet Life Cycle Impacts}

Use of the 'fleet lifetime' functional unit as opposed to the more common 'vehicle lifetime' or 'vehicle-km' provides a unique perspective on the potential unintended consequences of range limited fleets, e.g. BEBs. The assumption that a new technology can adequately fulfil the same heavy-duty requirement as the established diesel drivetrain has been challenged in this paper, revealing that TCO and LC-GHG results are less pronounced when conducting a fleet-by-fleet analysis of BEBs. Results of this study aligns with previous fleet assessments; 
Meinrenken [62] showed that GHG emissions savings from electrified transport in a fleet configuration is lower than what was previously considered when assessing vehicle performance on a per-km basis. Service frequency influences fleet size during off-peak periods, where passenger capacity and range restrictions largely dictate the peak vehicle requirement. Use of the fleet lifetime functional unit has revealed that less frequent, higher capacity DD vehicles offer greater TCO and LC-GHG savings than SD fleets. This fleet analysis approach can be adapted to other applications, e.g. other public transport services (taxis), logistics (heavy goods vehicles, transit vans), and utility services (refuse trucks).

\subsection{Framework Advantages, Limitations and Future Work}

The framework developed was intended to allow users to predict and quantify the potential economic and environmental impact of an alternative bus technology relative to a conventional diesel fleet. Users of the framework are expected to consult with all stakeholders, minimizing individual bias when selecting shape functions by including expert option or empirical findings. The framework is not intended to produce precise output values, but is a first port of call to gain a high level understanding of key life cycle sensitivities before exploring further complexities by using either higher fidelity drivetrain models [90] or revisiting input assumptions used when additional knowledge is gained. For less established technologies, uncertainty is inevitable, and users of this framework should seek to ensure model inputs are valid and representative of a given scenario. Setting data quality requirements would ensure transparency and applicability of results [14].

The current novel fleet sizing capability is designed to predict the required fleet and infrastructure size needed to fulfil the same function as a conventional diesel fleet. The fleet sizing model assumes that peak and offpeak conditions are two distinct periods, allowing for a minimal number of inputs, but limits analysis to the 'average vehicle' in the fleet. The vehicle dynamics models incorporated in the life cycle model can rapidly predict energy consumption over a drive cycle and account for mass changes (due to passengers or ESS selection) and other vehicle design parameters. This allows designers to realize the potential benefits and consequences of a new technology at an earlier stage where key design decisions are made, and little is known about the system (or life cycle impacts). Along with the fleet sizing model, the vehicle dynamics models are the most complex high-fidelity models in the framework - a conscious decision to ensure an appropriate balance between model fidelity and usefulness. This could potentially limit future case studies to specific operational situations similar to the case study presented, hence to enable a more universal approach, future work will entail the incorporation of more flexible timetable scheduling and time-dependent passenger load predictions into the fleet model.

Use of a hybrid-LCA model, complemented by life cycle costing, enables the evaluation of a comprehensive system boundary, but at the expense of a deeper understanding of the impacts of manufacturing, maintenance and infrastructure phases. Due to the 'no silver bullet' nature of vehicle LCAs, there is a case for constructing higher fidelity process-based models for these often-neglected phases in life cycle studies to gain a greater understanding of key parameters and multifaceted interactions to assist with reducing cost and environmental impacts.

The BEB ESS sizing model uses the predetermined maximum passenger capacity to calculate available ESS mass; future iterations could look at the effect of decreasing ESS size and increasing passenger capacity and possible implications for fleet size and life cycle impacts. The ESS is assumed to be capable of coping with the high currents from opportunity charging infrastructure [91]. Charge rate constraints are not contained in the model, but experts should be consulted, or higher fidelity models utilized to check if the selected ESS is applicable. Recent studies have shown that the time of day of charging and demand charges can influence TCO and LC-GHG emissions, as BEBs can avail from off-peak discounts and lower grid emissions at night [92].

\section{Conclusions}

The aim of this study is to develop a framework to investigate bus fleet operation in terms of the risk and uncertainty of an alternative drivetrain technology's ability to mitigate life cycle costs and greenhouse gas emissions. The intended application of the framework is to provide stakeholders (i.e. manufacturers and operators) with evidence to support the decision-making process for identifying and implementing new bus fleet technologies. The fleet analysis approach coupled with an extensive life cycle modelling framework adds to the current body of transport-based life cycle assessment research by providing a novel probabilistic capability for making comparative assertions about life cycle impacts on a fleet-by-fleet level as well as the traditional vehicleby-vehicle comparison. Probabilistic simulation was utilized in the evaluation of multiple diesel, micro-hybrid, 
mild-hybrid and battery-electric bus fleet scenarios for a high capacity urban case study in the framework revealing the following conclusions:

- The conventional vehicle-by-vehicle comparison neglects the influence that passenger capacity and range limitations have on fleet and infrastructure sizing, underestimating capital costs and greenhouse gas emissions of these phases.

- A fleet modelling approach enables a fairer assessment of an alternative drivetrain technology's ability to provide the same function as a conventional diesel fleet.

- There is an $80 \%$ probability that a micro-hybrid double-deck fleet will provide the largest life cycle cost savings $(18.7 \%)$ of all scenarios assessed when compared to the conventional single-deck diesel fleet baseline result.

- There is an $80 \%$ probability that a mild-hybrid single-deck fleet with a lithium titanate oxide battery will provide the largest life cycle greenhouse gas emissions savings (20.8\%) of all scenarios assessed.

- Double-deck micro and mild hybrid fleets are the most cost effective at saving both life cycle costs and greenhouse gas emissions of all scenarios.

- Future research into increasing the fidelity and functionality of fleet sizing and drive cycle models should be considered to enable for a more universal approach, enhance the understanding of life cycle sensitivities and allow for the assessment of additional alternative bus technologies.

\section{Funding}

This work was supported by the Northern Ireland Department for the Economy and Wrights Group Ltd.

\section{Acknowledgments}

The authors would like to thank the reviewers for their insightful comments and efforts towards improving the manuscript. The authors would like to express their gratitude to the funding bodies, to Skeleton Technologies for providing information to help calculate emission factors for the manufacturing of ultracapacitors and to Wrights Group Ltd for providing vehicle and emissions data. The authors would also like to recognize the continued support from members of the Sir William Wright Technology Centre (W-Tech) at Queen's University Belfast.

\section{References}

[1] IPCC. Summary for Policymakers. Global Warming of $15^{\circ} \mathrm{C}$ An IPCC Special Report on the Impacts of Global Warming of $15^{\circ} \mathrm{C}$ above Pre-Industrial Levels and Related Global Greenhouse Gas Emission Pathways, in the Context of Strengthening the Global Response to the Threat of Climate Change, 2018.

[2] Butler CD. Climate change, health and existential risks to civilization: A comprehensive review (1989-2013). International Journal of Environmental Research and Public Health 2018;15. doi:10.3390/ijerph15102266.

[3] Sims R, Schaeffer R, Creutzig F, Cruz-Núñez X, D’Agosto M, Dimitriu D, et al. Transport. In: Edenhofer O, Pichs-Madruga R, Y. Sokona, E. Farahani S, Kadner KS, Adler A, Baum I, et al., editors. Climate Change 2014: Mitigation of Climate Change. Contribution of Working Group III to the Fifth Assessment Report of the Intergovernmental Panel on Climate Change, Cambridge University Press, Cambridge, United Kingdom and New York, NY, USA; 2014, p. 599-670.

[4] Bruckner T, Bashmakov IA, Mulugetta Y, Chum H, De la Vega Navarro A, Edmonds J, et al. Energy systems. In: Edenhofer O, Pichs-Madruga R, Y. Sokona, E. Farahani S, Kadner KS, Adler A, Baum I, et al., editors. Climate Change 2014: Mitigation of Climate Change. Contribution of Working Group III to the Fifth Assessment Report of the Intergovernmental Panel on Climate Change, Cambridge University Press, Cambridge, United Kingdom and New York, NY, USA; 2014, p. 511-97.

[5] LowCVP. The Low Emission Bus Guide. London: Low Carbon Vehicle Partnership; 2016.

[6] SCI Verkehr GmbH. Buses - Global Market Trends. Hamburg: 2017.

[7] European Parliament. Regulation (EC) No 595/2009 on type-approval of motor vehicles and engines with respect to emissions from heavy duty vehicles (Euro VI) and on access to vehicle repair and maintenance information and amending Regulation (EC) No 715/2007 and Directive 2007. Official Journal of the European Union 2009;52.

[8] IPCC. Climate change 2014. Synthesis Report. Contribution of Working Groups I, II and III to the Fifth Assessment Report of the Intergovernmental Panel on Climate Change 2014:151. doi:10.1017/CBO9781107415324.

[9] European Commission. Energy prices and costs in Europe. Brussels: 2019.

[10] Rogge M, Hurk E Van Der, Larsen A, Uwe D. Electric bus fleet size and mix problem with optimization of charging infrastructure. Applied Energy 2018;211:282-95. doi:10.1016/j.apenergy.2017.11.051.

[11] Lajunen A. Energy consumption and cost-benefit analysis of hybrid and electric city buses. Transportation Research Part C: Emerging Technologies 2014;38:1-15. doi:10.1016/j.trc.2013.10.008. 
[12] Garcia R, Freire F. A review of fleet-based life-cycle approaches focusing on energy and environmental impacts of vehicles. Renewable and Sustainable Energy Reviews 2017;79:935-45. doi:10.1016/j.rser.2017.05.145.

[13] ISO. BS EN ISO 14040:2006 Environmental Management - Life Cycle Assessment - Principles and Framework. International Organisation for Standardization 2006;14040.

[14] ISO. BS EN ISO 14044:2006 Environmental Management - Life Cycle Assessment - Requirements and Guidelines. International Organisation for Standardization 2006;14044.

[15] Messagie M, Boureima FS, Coosemans T, Macharis C, Mierlo J Van. A range-based vehicle life cycle assessment incorporating variability in the environmental assessment of different vehicle technologies and fuels. Energies 2014;7:1467-82. doi:10.3390/en7031467.

[16] McCleese DL, LaPuma PT. Using monte carlo simulation in life cycle assessment for electric and internal combustion vehicles The International Journal of Life Cycle Assessment 2002;7:230-6. doi:10.1007/BF02978878.

[17] Hubbard DW. How to Measure Anything: Finding the Value of "Intangibles" in Business. 2nd ed. Hoboken, NJ: John Wiley \& Sons, Inc; 2014. doi:10.1002/9781118983836.

[18] Vuchic VR. Urban Transit: Operations, Planning, and Economics. 1st ed., Hoboken, NJ: John Wiley \& Sons Inc; 2005.

[19] Hassold S, Ceder AA. Public transport vehicle scheduling featuring multiple vehicle types. Transportation Research Part B: Methodological 2014;67:129-43. doi:10.1016/j.trb.2014.04.009.

[20] McKenzie EC, Durango-Cohen PL. Environmental life-cycle assessment of transit buses with alternative fuel technology. Transportation Research Part D: Transport and Environment 2012;17:39-47. doi:10.1016/j.trd.2011.09.008.

[21] Durango-Cohen PL, Croft-McKenzie E. Trading off costs, environmental impact, and levels of service in the optimal design of transit bus fleets. Transportation Research Procedia 2017;23:1020-32. doi:10.1016/j.trpro.2017.05.056.

[22] Chan S, Miranda-Moreno LF, Alam A, Hatzopoulou M. Assessing the impact of bus technology on greenhouse gas emissions along a major corridor: A lifecycle analysis. Transportation Research Part D: Transport and Environment 2013;20. doi:10.1016/j.trd.2013.01.004.

[23] Mahmoud M, Garnett R, Ferguson M, Kanaroglou P. Electric buses: A review of alternative powertrains. Renewable and Sustainable Energy Reviews 2016;62:673-84. doi:10.1016/j.rser.2016.05.019.

[24] Lajunen A, Lipman T. Lifecycle cost assessment and carbon dioxide emissions of diesel, natural gas, hybrid electric, fuel cell hybrid and electric transit buses. Energy 2016;106:329-42. doi:10.1016/j.energy.2016.03.075.

[25] Lajunen A. Lifecycle costs and charging requirements of electric buses with different charging methods. Journal of Cleaner Production 2018;172:56-67. doi:10.1016/j.jclepro.2017.10.066.

[26] Vepsäläinen J, Baldi F, Lajunen A, Kivekäs K, Tammi K. Cost-Benefit Analysis of Electric Bus Fleet with Various Operation Intervals. IEEE Conference on Intelligent Transportation Systems, Proceedings, ITSC 2018;2018-Novem:1522-7. doi:10.1109/ITSC.2018.8569583.

[27] Ercan, Zhao Y, Tatari O, Pazour JA. Optimization of transit bus fleet's life cycle assessment impacts with alternative fuel options. Energy 2015;93:323-34. doi:10.1016/j.energy.2015.09.018.

[28] Islam A, Lownes N. When to go electric? A parallel bus fleet replacement study. Transportation Research Part D: Transport and Environment 2019;72:299-311. doi:10.1016/j.trd.2019.05.007.

[29] Su Y, Liu X, Lu G, Fan W. Optimal Design of Bus Routes for Different Vehicle Types Considering Various Driving Regimes and Environmental Factors. Transportation Research Record 2019;2673:299-316. doi:10.1177/0361198119841566.

[30] Xylia M, Leduc S, Laurent AB, Patrizio P, van der Meer Y, Kraxner F, et al. Impact of bus electrification on carbon emissions: The case of Stockholm. Journal of Cleaner Production 2019;209:74-87. doi:10.1016/j.jclepro.2018.10.085.

[31] DeLaurentis L, Mavris D. Uncertainty modeling and management in multidisciplinary analysis and synthesis. 38th Aerospace Sciences Meeting \& Exhibit, Reno, NV: 2000, p. 422. doi:10.2514/6.2000-422.

[32] Edwards R, Hass H, Larivé J-F, Lonza L, Mass H, Rickeard D. WELL-TO-WHEELS Report Version 4.a JEC WELL-TOWHEELS ANALYSIS WELL-TO-WHEELS ANALYSIS OF FUTURE AUTOMOTIVE FUELS AND POWERTRAINS IN THE EUROPEAN CONTEXT. 2014. doi:10.2790/95533.

[33] Argonne National Laboratory. GREET® The Greenhouse gases, Regulated Emissions, and Energy use in Transportation Model 2017. https://greet.es.anl.gov/index.php (accessed March 9, 2017).

[34] Ercan T, Tatari O. A hybrid life cycle assessment of public transportation buses with alternative fuel options. International Journal of Life Cycle Assessment 2015;20. doi:10.1007/s11367-015-0927-2.

[35] Ribau JP, Silva CM, Sousa JMC. Efficiency, cost and life cycle CO2 optimization of fuel cell hybrid and plug-in hybrid urban buses. Applied Energy 2014;129:320-35. doi:10.1016/j.apenergy.2014.05.015.

[36] Ribau JP, Sousa JMC, Silva CM. Reducing the carbon footprint of urban bus fleets using multi-objective optimization. Energy 2015;93:1089-104. doi:10.1016/j.energy.2015.09.112.

[37] Zhou B, Wu Y, Zhou B, Wang R, Ke W, Zhang S, et al. Real-world performance of battery electric buses and their life-cycle benefits with respect to energy consumption and carbon dioxide emissions. Energy 2016;96:603-13.

doi:10.1016/j.energy.2015.12.041.

[38] Dreier D, Silveira S, Khatiwada D, Fonseca KVO, Nieweglowski R, Schepanski R. Well-to-Wheel analysis of fossil energy use and greenhouse gas emissions for conventional, hybrid-electric and plug-in hybrid-electric city buses in the BRT system in 
Curitiba, Brazil. Transportation Research Part D: Transport and Environment 2018;58:122-38. doi:10.1016/j.trd.2017.10.015.

[39] Szumska E, Pawełczyk M, Pistek V. Evaluation of the Life Cycle Costs for Urban Buses Equipped with Conventional and Hybrid Drive Trains. The Archives of Automotive Engineering 2019;83:73-86.

[40] Argonne National Laboratory. Alternative Fuel Life-Cycle Environmental and Economic Transportation (AFLEET) Tool 2017. https://greet.es.anl.gov/afleet_tool (accessed March 9, 2017).

[41] GHGenius. GHGenius: A model for lifecycle assessment of transportation fuels 2015. https://ghgenius.ca/ (accessed April 12, 2017).

[42] Cooney G, Hawkins TR, Marriott J. Life cycle assessment of diesel and electric public transportation buses. Journal of Industrial Ecology 2013;17. doi:10.1111/jiec.12024.

[43] Harris A, Soban D, Smyth BM, Best R. Assessing life cycle impacts and the risk and uncertainty of alternative bus technologies. Renewable and Sustainable Energy Reviews 2018;97:569-79. doi:10.1016/j.rser.2018.08.045.

[44] Harris A, Soban D, Smyth BM, Best R. Development of a Whole Life Cycle Economic and Environmental Impact Technology Assessment Tool for Alternative Driveline Bus Fleets. 12th Conference on Sustainable Development of Energy, Water and Environment Systems, Dubrovnik: 2017.

[45] Fitch P, Cooper JS. Life-cycle modeling for adaptive and variant design. Part 1: Methodology. Research in Engineering Design 2005;15:216-28. doi:10.1007/s00163-004-0055-7.

[46] Ercan T, Tatari O. A hybrid life cycle assessment of public transportation buses with alternative fuel options. International Journal of Life Cycle Assessment 2015;20:1213-31. doi:10.1007/s11367-015-0927-2.

[47] Vepsäläinen J, Ritari A, Lajunen A, Kivekäs K, Tammi K. Energy uncertainty analysis of electric buses. Energies 2018;11. doi:10.3390/en11123267.

[48] Raychaudhuri S. Introduction to Monte Carlo Simulation. Simulation Conference, 2008 WSC 2008 2008:91-100. doi:10.1109/WSC.2008.4736059.

[49] Ally J, Pryor T. Life cycle costing of diesel, natural gas, hybrid and hydrogen fuel cell bus systems: An Australian case study. Energy Policy 2016;94. doi:10.1016/j.enpol.2016.03.039.

[50] Göhlich D, Fay T, Jefferies D, Lauth E, Kunith A, Zhang X. Design of urban electric bus systems. Design Science 2019;4:1-28. doi:10.1017/dsj.2018.10.

[51] ACEA (European Automobile Manufacturers Association). Vehicles in use - Europe 2018. ACEA Report 2018.

[52] Heywood JB. Internal Combustion Engine Fundamentals. vol. 21. New York: McGraw-Hill; 1988. doi:10.1002/9781118991978.hces077.

[53] Robert Bosch GmbH. Bosch Automotive Handbook. 9th ed. John Wiley \& Sons Ltd; 2014.

[54] Dhand A, Cho B, Walker A, Muncey A, Kok D, Karden E, et al. Stop-Start Micro Hybrid: An Estimation of Automatic Engine Stop Duration in Real World Usage. SAE Technical Paper 2009-01-1336, United States: SAE International; 2009.

doi:https://doi.org/10.4271/2009-01-1336.

[55] Albers J, Meissner E, Shirazi S. Lead-acid batteries in micro-hybrid vehicles. Journal of Power Sources 2011;196:3993-4002. doi:10.1016/j.jpowsour.2010.11.094.

[56] Wrights Group Ltd. Wrightbus Euro 6 Product Range n.d. http://www.wrightbusinternational.com/datasheets/euro6productrange.pdf (accessed July 20, 2017).

[57] Abdul-Manan AFN. Uncertainty and differences in GHG emissions between electric and conventional gasoline vehicles with implications for transport policy making. Energy Policy 2015;87:1-7. doi:10.1016/j.enpol.2015.08.029.

[58] Orbaiz P, van Dijk N, Cosentino S, Oxenford N, Carignano M, Nigro NM. A Technical, Environmental and Financial Analysis of Hybrid Buses Used for Public Transport. WCX World Congress Experience 2018. doi:https://doi.org/10.4271/2018-01-0424.

[59] Automotive Council UK, Advanced Propulsion Centre UK. Bus Roadmap 2017.

[60] Wrights Group Ltd. Advanced driveline technology. Brochure 2017:1-11. http://www.wrightsgroup.com/Products/AdvancedDriveline-Technology (accessed August 2, 2019).

[61] Barbosa FC. Pure Electric Bus Traction Technology Overview - A Path Towards Enhanced Environmental Performance and Efficiency for Transit Bus Fleets 2014-36-0205 E. SAE Technical Paper 2014.

[62] Meinrenken CJ, Lackner KS. Fleet view of electrified transportation reveals smaller potential to reduce GHG emissions. Applied Energy 2015;138. doi:10.1016/j.apenergy.2014.10.082.

[63] Tsiropoulos I, Tarvydas D, Lebedeva N. Li-ion batteries for mobility and stationary storage applications - Scenarios for costs and market growth, EUR 29440 EN. Luxembourg: 2018. doi:10.2760/87175.

[64] Mohamed M, Farag H, El-Taweel N, Ferguson M. Simulation of electric buses on a full transit network: Operational feasibility and grid impact analysis. Electric Power Systems Research 2017;142:163-75. doi:10.1016/j.epsr.2016.09.032.

[65] Bi Z, Keoleian GA, Ersal T. Wireless charger deployment for an electric bus network: A multi-objective life cycle optimization. Applied Energy 2018;225:1090-101. doi:10.1016/j.apenergy.2018.05.070.

[66] Sánchez-Martínez GE, Koutsopoulos HN, Wilson NHM. Optimal allocation of vehicles to bus routes using automatically collected data and simulation modelling. Research in Transportation Economics 2016;59:1-9. doi:10.1016/j.retrec.2016.06.003.

[67] Briggs I, Murtagh M, Kee R, McCullough G, Douglas R. Sustainable non-automotive vehicles: The simulation challenges. Renewable and Sustainable Energy Reviews 2016. doi:10.1016/j.rser.2016.02.018. 
[68] Gao Z, Lin Z, LaClair TJ, Liu C, Li JM, Birky AK, et al. Battery capacity and recharging needs for electric buses in city transit service. Energy 2017;122:588-600. doi:10.1016/j.energy.2017.01.101.

[69] Carignano MG, Nigro NM, Junco S, Orbaiz P. Hybridisation effect on operating costs and optimal sizing of components for hybrid electric vehicles. International Journal of Simulation and Process Modelling 2017;12:221-34.

doi:10.1504/ijspm.2017.10006527.

[70] Ribau JP, Sousa JMC, Silva CM. Reducing the carbon footprint of urban bus fleets using multi-objective optimization. Energy 2015;93. doi:10.1016/j.energy.2015.09.112.

[71] Deloitte. Cost and Efficiency Review of Dublin Bus and Bus Éireann Contents 2009:88.

[72] Wang P, Deng X, Zhou H, Yu S. Estimates of the social cost of carbon: A review based on meta-analysis. Journal of Cleaner Production 2019;209:1494-507. doi:10.1016/j.jclepro.2018.11.058.

[73] Pearce D. The Social Cost of Carbon and its Policy Implications. Oxford Review of Economic Policy 2003;19:362-84. doi:10.1093/oxrep/19.3.362.

[74] Evans S, Pidcock R, Yeo S. Q\&A: The social cost of carbon. Carbon Brief 2017. https://www.carbonbrief.org/qa-social-costcarbon (accessed July 5, 2019).

[75] Department for Business Energy and Industrial Strategy (BEIS). Updated short-term traded carbon values used for modelling purposes 20182019.

[76] HM Treasury. The Green Book : Appraisal and Evaluation in Central Government. Evaluation 2011:118. doi:http://greenbook.treasury.gov.uk/index.htm.

[77] LowCVP. Testing \& Accreditation (LCEB Certification) 2017. http://www.lowcvp.org.uk/initiatives/lceb/lceb-testing.htm (accessed May 11, 2017).

[78] Transport for London. Route 159 now served by New Routemaster buses. Press Release 2015.

[79] Transport for London. TfL Bus User Survey 20142014.

[80] Transport for London. Route 159 - Bus Timetable 2018. https://tfl.gov.uk/bus/timetable/159?fromId=490001279E (accessed November 21, 2018).

[81] WAVE Inc. Long Beach Transit (LBT). Press Release 2018. https://waveipt.com/long-beach-transit-lbt/ (accessed July 7, 2019).

[82] Ruiz J, Long Beach Post. Wireless charging is now a reality for Long Beach's battery electric bus fleet. News Article 2018.

[83] Kunith A, Mendelevitch R, Goehlich D. Electrification of a city bus network - An optimization model for cost-effective placing of charging infrastructure and battery sizing of fast charging electric bus systems. International Journal of Sustainable Transport 2017;11:707-20. doi:10.1080/15568318.2017.1310962.

[84] Soban DS, Mavris DN. Assessing the Impact of Technology on Aircraft Systems Using Technology Impact Forecasting. Journal of Aircraft 2013;50:1380-93. doi:10.2514/1.C031871.

[85] Soban DS, Zeune C. Technology assessment for a complex aircraft system using technology scenarios. The Journal of Defense Modeling and Simulation: Applications, Methodology, Technology 2014. doi:10.1177/1548512914540230.

[86] BEIS. Updated Energy and Emissions Projections 2018 - Appendix M: Growth Assumptions and Prices. 2018.

[87] Lin B, Tan R. Are people willing to pay more for new energy bus fares? Energy 2017;130:365-72. doi:10.1016/j.energy.2017.04.153.

[88] Transport for London. Proposals to improve air quality Report to the Mayor on consultation 2017.

[89] Mayor of London. Mayor's Transport Strategy. London: 2018.

[90] Stevens G, Murtagh M, Kee R, Early J, Douglas R, Best R. Development of a Vehicle Model Architecture to Improve Modeling Flexibility. SAE International Journal of Engines 2017;10. doi:10.4271/2017-01-1138.

[91] Rothgang S, Rogge M, Becker J, Sauer DU. Battery Design for Successful Electrification in Public Transport. Energies 2015;8:6715-37. doi:10.3390/en8076715.

[92] Bi Z, Song L, De Kleine R, Mi CC, Keoleian GA. Plug-in vs. wireless charging: Life cycle energy and greenhouse gas emissions for an electric bus system. Applied Energy 2015;146. doi:10.1016/j.apenergy.2015.02.031. 